\title{
Cortical Potentials Evoked by Subthalamic Stimulation Demonstrate a Short Latency Hyperdirect Pathway in Humans
}

\author{
Svjetlana Miocinovic, ${ }^{1}$ Coralie de Hemptinne, ${ }^{2}$ Witney Chen, ${ }^{2}$ Faical Isbaine,${ }^{4}$ Jon T. Willie, ${ }^{4}$ Jill L. Ostrem, ${ }^{3}$ \\ and $\odot$ Philip A. Starr ${ }^{2}$ \\ ${ }^{1}$ Department of Neurology, Emory University, Atlanta, Georgia 30329, Departments of ${ }^{2}$ Neurological Surgery, ${ }^{3}$ Neurology, University of California San \\ Francisco, San Francisco, California 94143, and ${ }^{4}$ Department of Neurosurgery, Emory University, Atlanta, Georgia 30322
}

\begin{abstract}
A monosynaptic projection from the cortex to the subthalamic nucleus is thought to have an important role in basal ganglia function and in the mechanism of therapeutic subthalamic deep-brain stimulation, but in humans the evidence for its existence is limited. We sought physiological confirmation of the cortico-subthalamic hyperdirect pathway using invasive recording techniques in patients with Parkinson's disease (9 men, 1 woman). We measured sensorimotor cortical evoked potentials using a temporary subdural strip electrode in response to low-frequency deep-brain stimulation in patients undergoing awake subthalamic or pallidal lead implantations. Evoked potentials were grouped into very short latency $(<2 \mathrm{~ms})$, short latency $(2-10 \mathrm{~ms})$, and long latency $(10-100 \mathrm{~ms})$ from the onset of the stimulus pulse. Subthalamic and pallidal stimulation resulted in very short-latency evoked potentials at $1.5 \mathrm{~ms}$ in the primary motor cortex accompanied by EMG-evoked potentials consistent with corticospinal tract activation. Subthalamic, but not pallidal stimulation, resulted in three short-latency evoked potentials at $2.8,5.8$, and $7.7 \mathrm{~ms}$ in a widespread cortical distribution, consistent with antidromic activation of the hyperdirect pathway. Long-latency potentials were evoked by both targets, with subthalamic responses lagging pallidal responses by $10-20 \mathrm{~ms}$, consistent with orthodromic activation of the thalamocortical pathway. The amplitude of the first short-latency evoked potential was predictive of the chronic therapeutic stimulation contact.
\end{abstract}

Key words: cortical projections; DBS; deep-brain stimulation; electrocorticography; globus pallidus; hyperdirect pathway

Significance Statement

This is the first physiological demonstration of the corticosubthalamic hyperdirect pathway and its topography at high spatial resolution in humans. We studied cortical potentials evoked by deep-brain stimulation in patients with Parkinson's disease undergoing awake lead implantation surgery. Subthalamic stimulation resulted in multiple short-latency responses consistent with activation of hyperdirect pathway, whereas no such response was present during pallidal stimulation. We contrast these findings with very short latency, direct corticospinal tract activations, and long-latency responses evoked through polysynaptic orthodromic projections. These findings underscore the importance of incorporating the hyperdirect pathway into models of human basal ganglia function.

\section{Introduction}

The corticosubthalamic hyperdirect pathway is a monosynaptic axonal connection from frontal cortex to the subthalamic nu-

Received May 24, 2018; revised July 23, 2018; accepted July 23, 2018.

Author contributions: C.d.H., W.C., F.I., J.T.W., J.L.O., and P.A.S. edited the paper. S.M. and P.A.S. designed research; S.M., C.d.H., F.I., J.T.W., and P.A.S. performed research; S.M., W.C., and F.I. analyzed data; S.M. wrote the paper.

This work was supported by the American Brain Foundation Clinical Research Training Fellowship, and National Institutes of Health and National Institute of Neurological Disorders and Stroke (K23NS097576, and R01NS090913). The authors declare no competing financial interests.

Correspondence should be addressed to Dr. Svjetlana Miocinovic, Emory University, Department of Neurology, 12 Executive Park Northeast, Atlanta, GA 30329. E-mail: svjetlana.Miocinovi@@emory.edu. cleus (STN). It bypasses the striatum and thus functions in parallel, rather than in series, with the classical direct and indirect pathways. Its anatomic connectivity has been defined in rodents and nonhuman primates from histological tracing studies (Monakow et al., 1978; Canteras et al., 1988; Nambu et al., 1996). Its physiological properties have been studied in rodents using intracellular recordings and evoked potentials (Kitai and Deniau, 1981; Maurice et al., 1998; Li et al., 2007; Kumaravelu et al., 2018) and in nonhuman primates using evoked potentials (Devergnas 
and Wichmann, 2011). In rodents the hyperdirect pathway is formed by axon collaterals from corticospinal and corticobulbar fiber tracts passing through the internal capsule, although some may be direct connections (Kita and Kita, 2012).

In contemporary models of the basal ganglia-thalamocortical motor loop, this pathway has assumed increasing importance, as it is positioned to provide a rapid global inhibition that may shape temporal dynamics of action selection and cancellation (Gurney et al., 2001; Nambu, 2005; Kumaravelu et al., 2016). In rodent models of Parkinson's disease, the hyperdirect pathway is thought to be critical in the mechanism of therapeutic STN deepbrain stimulation (DBS; Dejean et al., 2009; Gradinaru et al., 2009; Li et al., 2012; Sanders and Jaeger, 2016; Anderson et al., 2018). Activation of this pathway during DBS occurs because the extracellular voltage field induced by DBS generates an action potential antidromically toward the cell body in the cortex, as well as orthodromically toward terminal synapses (Miocinovic et al., 2006; Gunalan et al., 2017).

Despite increasing scientific and clinical interest in the hyperdirect pathway, its existence in humans has not been conclusively demonstrated. MRI tractography studies have suggested the presence of the hyperdirect pathway (Aron et al., 2007; Brunenberg et al., 2012; Lambert et al., 2012; Plantinga et al., 2016), and TMS experiments alluded to its presence (Udupa et al., 2016). However, there has been no unambiguous electrophysiologic confirmation of its existence or delineation of its topography at high spatial resolution. The activation of direct cortical projections into the basal ganglia can be quantified by measuring shortlatency cortical potentials evoked by DBS (Devergnas and Wichmann, 2011). Previous human studies that attempted to measure hyperdirect pathway activation in the cortex suggested a wide range for its conduction velocity $(7-60 \mathrm{~m} / \mathrm{s}$; Walker et al., 2012; Kelley et al., 2018). Physiologic demonstration of antidromic hyperdirect transmission would require temporal or spatial separation between evoked potentials generated via this pathway, versus alternative mechanisms such as current spread to pyramidal fibers bordering the STN or orthodromic cortical activation via globus pallidus (GP) and thalamus. Of note, antidromic activation of the primary motor (M1) pyramidal neurons has a very short latency, depending on the length and diameter of the axon, and is on the order of 1-2 ms (Li et al., 2007; Fukaya et al., 2011), such that separation of hyperdirect activation from pyramidal tract activation is technically challenging.

Electrocorticography (ECoG) recordings performed during DBS implantation surgery provide excellent spatial and temporal resolution, high signal-to-noise ratio, and can be done safely without modifying surgical exposure (Panov et al., 2017). We show that antidromic activation of the hyperdirect pathway can be quantified by measuring short-latency cortical evoked potentials (EPs) in response to STN stimulation, that hyperdirect-mediated EPs are not present during GP DBS, and that this response can be distinguished from alternative sources of motor cortex activation that can arise from stimulation in the STN region. Detection of hyperdirect activation can also provide an objective physiological predictor of clinically therapeutic STN DBS.

\section{Materials and Methods}

Patient selection. Patients with idiopathic Parkinson's disease scheduled to undergo STN or GP DBS surgery at University of California San Francisco or Emory University were recruited for the study ( 9 men, 1 woman). Informed consent was obtained before surgery under protocols approved by the Institutional Review Boards at both universities. All patients were aware that the temporary subdural ECoG recording strip was used strictly for research purposes.

Surgical process and electrocorticography strip localization. To record cortical potentials, a subdural ECoG strip (28 or 6 contacts; Ad-Tech) was placed on the surface of the brain through the same burr hole used for DBS implantation (Crowell et al., 2012; de Hemptinne et al., 2015; Panov et al., 2017). The 28-contact strip had two rows of fourteen 2-mmdiameter platinum contacts separated by $4 \mathrm{~mm}$. The 6-contact strip had one row of $4-\mathrm{mm}$-diameter platinum contacts separated by $10 \mathrm{~mm}$. The intended target location for the center of the strip was the arm area of M1, $3 \mathrm{~cm}$ from the midline and slightly medial to the hand knob. Recordings were performed at least $12 \mathrm{~h}$ after stopping all anti-parkinsonian medications and at least $30 \mathrm{~min}$ after stopping propofol. DBS electrodes were placed in the STN or GP with microelectrode guidance as previously described (Starr, 2002).

ECoG strip location was determined using intraoperative CT coregistered to the preoperative planning MRI using standard surgical planning software (Framelink 5.1, Medtronic). ECoG contact locations were classified as premotor (located anterior to precentral gyrus), M1 (over the precentral gyrus), primary sensory (S1; over the postcentral gyrus), and superior parietal lobule (posterior to postcentral gyrus) based on imaging localization. The location of the central sulcus with respect to ECoG contacts was confirmed with median nerve somatosensory-EPs and reversal of the $\mathrm{N} 20$ waveform indicating M1 location (Crowell et al., 2012). DBS contact coordinates were determined from intraoperative CT and preoperative MRI using Cranial Vault software (Neurotargeting).

Signal recordings. ECoG potentials were recorded using the Neuro Omega (Alpha Omega Engineering) or TDT PZ5 (Tucker Davis Technologies; Patients 1 and 2) acquisition systems. An ipsilateral scalp needle or ear electrode (Patients 6 and 10) was used as a recording reference while corresponding contralateral electrode served as the ground. Signals were amplified and acquired at $22 \mathrm{kHz}$ sampling rate with a built-in hardware bandpass filtering between 0.075 and $3500 \mathrm{~Hz}$ for Neuro Omega, and 24,414 Hz sampling rate and 1-10,000 Hz bandpass filter for TDT. Muscle activity was recorded using surface EMG from the contralateral arm (biceps, flexor carpi radialis, extensor carpi radialis, trapezius, and first dorsal interosseous), leg (tibialis anterior), and face (nasalis, genioglossus) using the same acquisition settings. Specific muscles recorded varied by patient, and channels that were unstable or noisy were excluded from analysis (on average 3.5 EMG channels were analyzed per patient, range 2-7). EMG was uninterpretable in three patients due to severe electrical noise (Patients 1, 2, 9).

EPs were recorded while patients were at rest. STN or GP stimulation was performed using the Neuro Omega (Patients 4, 5, 6, 10), Medtronic digital stimulator (model 8840; Patients 1, 2, 7-GP, 8, 9), Medtronic analog stimulator (model 3625; Patient 3), or Medtronic Activa PC implantable pulse generator (model 37601; Patient 7-STN). Low-frequency stimulation was performed at $10 \mathrm{~Hz}$ except in two patients (7 and 9) where $2 \mathrm{~Hz}$ was used. In four patients $(4,5,6,10)$, EPs were also recorded during high-frequency stimulation $(130-155 \mathrm{~Hz})$, and during monopolar stimulation for which a large surface electrode on the contralateral shoulder served as the positive contact (anode; denoted as $\mathrm{C}+$ ). Stimulation settings are described so that cathodic contact is followed by a minus $(-)$ and anodic by a plus $(+)$. Contact 0 was the most ventral (deepest) contact. Each stimulation setting was tested for $10-15 \mathrm{~s}$ with a 3-5 $\mathrm{s}$ pause between the settings. The number of settings tested varied between patients depending on the amount of time available intraoperatively (average 20, range 4-34). The order of stimulation settings was randomized in six patients. The stimulation contact and amplitude (1-5 mA) were varied most systematically. In three patients several pulse widths were tested, and in one patient positive repolarization phase of the stimulation waveform was varied in duration. Constant current stimulation was preferred to control the amount of charge injected. In cases where constant voltage stimulator was used, contact impedance was measured using a Medtronic digital stimulator (bipolar montage, $100 \mathrm{~Hz}$ ), and approximate stimulation current $(I)$ was calculated $(I=V / R$ where $V$ is the stimulation voltage 
Table 1. Experimental setup for each patient

\begin{tabular}{|c|c|c|c|c|c|c|c|c|c|}
\hline Patient & $\begin{array}{l}\text { DBS } \\
\text { target }\end{array}$ & ECoG side & $\begin{array}{l}\text { No. of } \\
\text { ECoG contacts }\end{array}$ & $\begin{array}{l}\text { ECoG laterality } \\
\text { at M1, mm }\end{array}$ & $\begin{array}{l}\text { DBS contact } \\
\text { spacing, mm }\end{array}$ & Stimulator used & $\begin{array}{l}\text { Stimulation } \\
\text { frequency, } \mathrm{Hz}\end{array}$ & $\begin{array}{l}\text { No. of stimulation } \\
\text { settings tested }\end{array}$ & $\begin{array}{l}\text { DBS lead } \\
\text { location }^{a}\end{array}$ \\
\hline 1 & STN & $\mathrm{R}$ & 28 & 41.5 & 1.5 & MDT digital & 10 & 18 & $12.7,-2.4,-4.0$ \\
\hline 2 & STN & $\mathrm{R}$ & 28 & 22.6 & 1.5 & MDT digital & 10 & 20 & $10.9,-1.6,-4.6$ \\
\hline 3 & STN & $\mathrm{R}$ & 28 & 35 & 0.5 & MDT analog & 10 & 18 & $13.1,-5.4,-6.1$ \\
\hline 4 & STN & $\mathrm{R}$ & 28 & 44 & 0.5 & Neuro 0mega & 10 & $34^{c}$ & $13.4,-1.3,-4.1$ \\
\hline 5 & STN & $\mathrm{R}$ & 28 & 27.5 & $0.5^{b}$ & Neuro Omega & 10 & $27^{c}$ & $9.3,-4.8,-7.3$ \\
\hline 6 & STN & $\mathrm{R}$ & 28 & 34 & 0.5 & Neuro Omega & 10 & $34^{c}$ & $\begin{array}{l}12.1,-4.9,-3.5 \\
-12.2,-4.9,-2.6\end{array}$ \\
\hline 7 & STN, GP & $\mathrm{L}$ & 6 & 32.8 & $0.5,1.5$ & IPG, MDT digital & 2 & 7,6 & $-23.0,1.5,-2.9$ \\
\hline 8 & GP & $\mathrm{L}$ & 6 & 28 & 1.5 & MDT digital & 10 & 7 & $-20.2,1.0,-4.4$ \\
\hline 9 & GP & $\mathrm{R}$ & 6 & 26.1 & 1.5 & MDT digital & 2 & 4 & $19.1,0.8,-4.8$ \\
\hline 10 & GP & $\mathrm{R}$ & 28 & 27.5 & 0.5 & Neuro Omega & 10 & $34^{c}$ & $21.9,2.0,-2.4$ \\
\hline
\end{tabular}

${ }^{a} x-, y-$, and $z$-coordinates of the most ventral DBS contact in the AC-PC space (with respect to midcommissural point).

${ }^{b}$ Eight-contact Boston Scientific lead.

Two to 10 additional high-frequency settings were tested.

MDT, Medtronic; IPG, implantable pulse generator.

and $R$ is the average prestimulation and poststimulation impedance for the given contacts).

Signal processing. Data analysis was performed using custom scripts in MATLAB vR2014a (MathWorks). ECoG potentials were re-referenced in a bipolar montage using adjacent contacts. Stimulus pulse start times were detected automatically from the ECoG or EMG channel with the largest stimulus artifact. ECoG and EMG potentials were aligned by stimulus start times and averaged to generate EPs. Approximately 100-150 trials were used for each DBS settings. The averaged baseline was corrected to zero using $1 \mathrm{~ms}$ of data before stimulus pulse, and a smoothing function (15-point window moving average) was applied. Peak latency, peak amplitude, and onset latency were determined visually from the smoothed signal. Both raw and smoothed signals were displayed for peak selection, and each peak (or trough) had to stand out visually above the noise level to be selected. Very short-latency EPs $(<2 \mathrm{~ms})$ were selected on raw (unsmoothed) signals.

The earliest short-latency peak or trough after the stimulus pulse (or after very short-latency EP) was defined as EP1 (see Fig. 2). The onset of EP1 was defined as the deflection toward the peak (or trough) after the end of stimulus artifact and signal return to baseline. In cases where this point could not be clearly identified due to the large stimulation artifact, EP1 was not defined ( $<2 \%$ of the recordings; stimulation artifact typically ended by $1 \mathrm{~ms}$ after stimulus onset). The onset of EP1 was used to define EP1 amplitude as the difference between the peak and onset voltage. In case very short-latency EP was present, EP1 amplitude was defined with respect to the preceding trough. Very short-latency EP was defined in a similar manner with respect to the deflection toward the peak after the end of stimulus artifact. Additional short-latency EPs (EP2 and EP3) were defined as subsequent peaks that occurred within the first $10 \mathrm{~ms}$. EP amplitude was defined as the voltage difference between the peak and preceding trough (and vice versa for troughs). Long latency potentials were determined using the same method. The first longlatency peak or trough (P1 or T1) was placed into a bin based on similar peak latencies across the channels and stimulation settings ( 5 bins from 10 to $100 \mathrm{~ms}$ ), and subsequent events were numbered sequentially (P2/T2 to P5/T5).

EP amplitudes and latencies were determined for each stimulation setting and each ECoG bipolar channel. Contact pairs spanning two different anatomical locations were not used for location-related analysis.

To compare the effect of monopolar and bipolar stimulation, we calculated bipolar stimulation amplitude necessary to produce the same size $\mathrm{EP}$ as $1 \mathrm{~mA}$ monopolar stimulation. This was calculated using the following formula: $\left(A_{M} / C_{M}\right) /\left(A_{B} / C_{B}\right)$, where $A_{M}$ is EP amplitude during monopolar stimulation, $C_{M}$ is monopolar stimulation current, $A_{B}$ is EP amplitude during bipolar stimulation, and $\mathrm{C}_{\mathrm{B}}$ is bipolar stimulation current. Calculation was done for stimulation settings using the same contact as the cathode, with other stimulation parameters held constant, and then averaged across all channels to yield one value per patient.
Statistical analysis. One-way ANOVA was performed to compare differences in EP amplitudes and latencies across different cortical locations and stimulation parameters. Post hoc paired $t$ tests with Bonferroni correction were performed to compare EPs between individual regions and stimulation parameters. Pearson coefficient was used to test for linear correlation between EP amplitudes and latencies, and between EP1 latency and recording strip location. A $p$ value $<0.05$ was considered statistically significant.

\section{Results}

We analyzed subdural cortical EP recordings from 10 patients ( 9 men, 1 woman) with Parkinson's disease: 6 with a DBS electrode in the STN, 3 with an electrode in the GP, and 1 with electrodes in the STN and GP (Table 1; Fig. $1 A-C$ ). The average ventral contact coordinates for the STN leads were $x=11.9 \pm 1.4 \mathrm{~mm}, y=$ $-3.6 \pm 1.8 \mathrm{~mm}, z=-4.6 \pm 1.6 \mathrm{~mm}$ (mean $\pm \mathrm{SD}$; Fig. $1 B$ ) and for GP leads were $x=21.1 \pm 1.8 \mathrm{~mm}, y=1.3 \pm 0.5 \mathrm{~mm}, z=$ $-3.6 \pm 1.2 \mathrm{~mm}$ (with respect to the midcommisural point; Fig. $1 C)$. A total of $4930 \mathrm{EP}$ averages were analyzed and 3611 included in location-related analysis (for which recording channels spanning different gyri were excluded). Cortical responses were separated into very short latency $(<2 \mathrm{~ms})$, short latency $(2-10 \mathrm{~ms})$, and long latency $(10-100 \mathrm{~ms})$ based on the timing of the EP peaks. These boundaries were determined post hoc based on the presence of three discrete EP latency clusters as discussed below. EPs even at very short latencies were distinct from the stimulation artifact. This was demonstrated by changing the location of positive (anodic) contact, which inverted the stimulation artifact without inversion of the EP waveform (Fig. 1D).

\section{Short-latency cortical EPs}

We observed short-latency $(2-10 \mathrm{~ms})$ cortical responses to STN stimulation and argue below that these result from antidromic activation of the hyperdirect pathway. These were evoked by STN stimulation in all patients and not by GP stimulation. They typically contained one to three peaks (Fig. $2 A-C$ ). Later peaks were sometimes present without the early ones. The presence of a short-latency EP and the complexity of the EP waveform (number of consecutive peaks/troughs) was highest in M1 and premotor areas, but EPs were also frequently observed in S1 and the superior parietal lobule (Fig. 2D). In M1, 71\% of cortical responses (all STN patients, all stimulation settings) included at least one short-latency EP. 
A

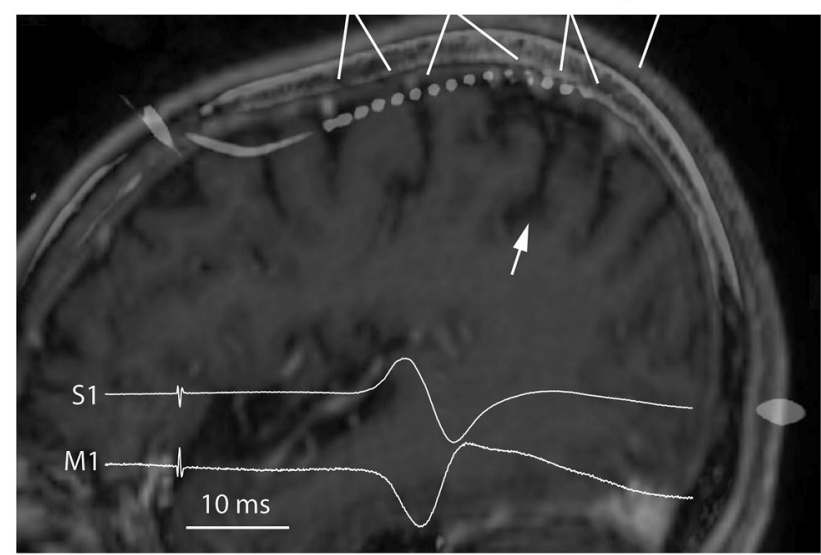

C

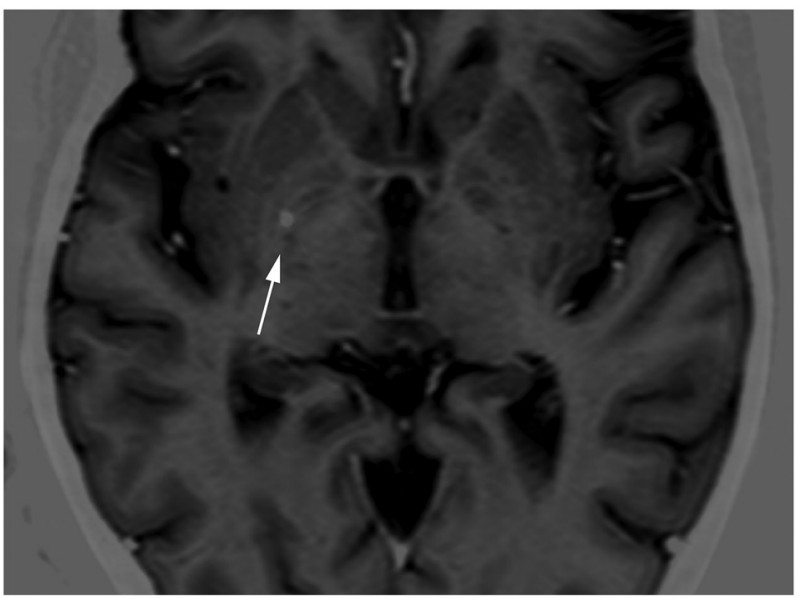

B

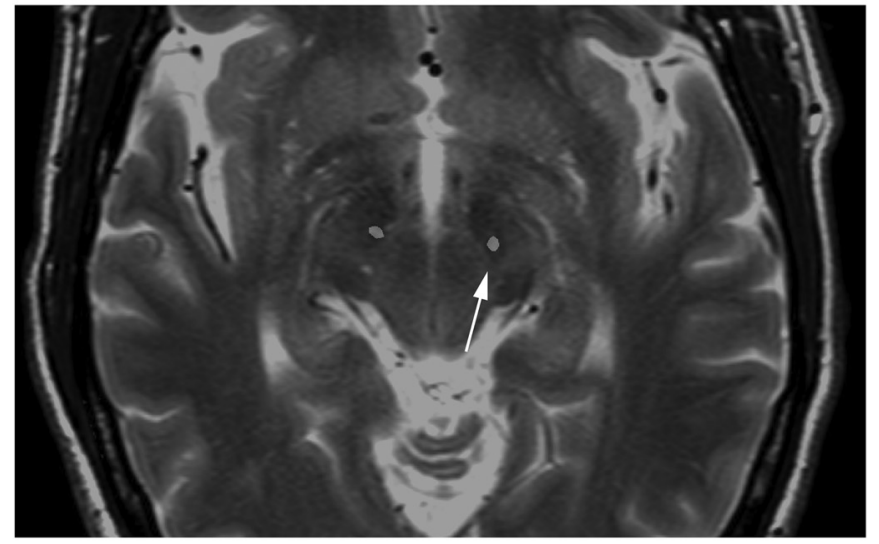

D

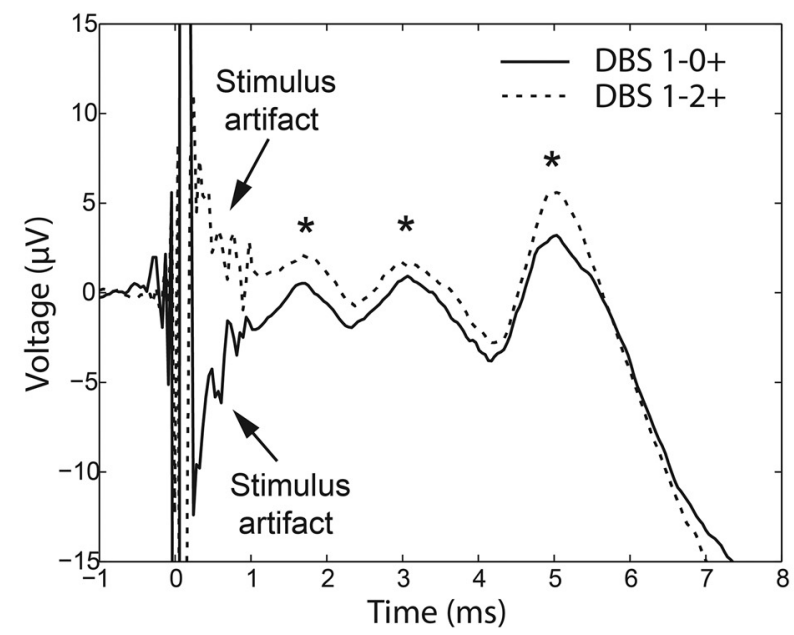

Figure 1. Recording and stimulation locations, and invariance of EP morphology to stimulus phase reversal. $\boldsymbol{A}$, Temporary subdural strip electrode was used to record EPs from the cortex (premotor, M1, S1, superior parietal lobule, $\sim 3 \mathrm{~cm}$ from midline) during low-frequency STN or GP DBS. Strip location was confirmed with median nerve somatosensory EP reversal (inset). White arrow indicates the central sulcus. $\boldsymbol{B}, \boldsymbol{C}$, DBS lead was implanted in the STN ( $\boldsymbol{B}$; axial slice, 4 mm below AC-PC plane) or GP (C; axial slice, at AC-PC plane) using standard microelectrode-guided technique. White arrow on MRI-CT coregistration indicates location of the lead used for evoking cortical responses. EC $0 \mathrm{G}$ recording strip was ipsilateral to DBS lead used for stimulation. D, Changing DBS-positive contact location reversed polarity of stimulation artifact, but cortical EPs remained upgoing (Patient 1, 3.4 mA, $60 \mu$ s). Asterisks denote EP peaks at 1.6, 3, and $5 \mathrm{~ms}$.

EP latency varied based on ECoG recording contact location, while the amplitude was always the largest in M1 (Fig. 3). The EP1 peak occurred on average $2.6 \pm 0.3 \mathrm{~ms}$ after the start of stimulus pulse with the onset latency of $1.8 \pm 0.3 \mathrm{~ms}$ (mean $\pm \mathrm{SD}$ ). The EP1 peak latency was the shortest in parietal and premotor regions $(2.3 \pm 0.2 \mathrm{~ms}$, both $)$ and the longest in M1 $(2.8 \pm 0.3 \mathrm{~ms}$; $F_{(3,1195)}=279.8, p<10^{-6}$, ANOVA). The EP2 peak latency was shortest in the premotor region $(4.1 \pm 0.6 \mathrm{~ms})$ and longest in parietal area $(6.3 \pm 1.5 \mathrm{~ms})$ followed by M1 $\left(5.8 \pm 1.0 \mathrm{~ms} ; F_{(3,976)}=153.1\right.$, $p<10^{-6}$, ANOVA). The EP3 latency was similar in all locations $\left(7.7 \pm 1.8 \mathrm{~ms} ; F_{(3,693)}=2.0, p=0.1\right.$, ANOVA $)$.

The data presented in the preceding figures were averaged for all STN patients, but these relations held true for individual patients as well and all demonstrated short-latency potentials across all cortical recording locations. The average EP1 peak latency in M1 ranged from $2.5 \pm 0.2 \mathrm{~ms}$ (Patient 3) to $3.1 \pm 0.2 \mathrm{~ms}$ (Patient $6)$. There was no correlation between the average M1 EP1 latency and the laterality of the recording strip from midline $(p=0.7)$. Because of the oblique DBS electrode trajectory, the most ventral contact was always the most medial and most posterior. Based on registration of the lead depth with the microelectrode recording map of the dorsal and ventral border of STN, for narrow quad- ripolar leads (3389), contacts $0-2$ were within STN, whereas contact 3 was placed in zona incerta. For wide quadripolar leads (3387), contacts 0 and 1 were within the STN. In Patient 5, with an 8-contact lead, contacts $2-4$ were in the STN. With all quadripolar leads, EP amplitudes were the largest when the cathode was set to the ventral two contacts (for Patient 5, contacts 2-4 had the largest EPs) and the smallest (or absent) for contacts outside the STN.

In animal studies, hyperdirect activation has also been associated with multiple short-latency peaks, and modeling studies suggest that the earliest is due to depolarization of pyramidal cells and their dendrites; whereas later ones are due to activation of recurrent collaterals or inhibitory interneurons (Li et al., 2007; Kumaravelu et al., 2018). If true in humans, we would expect amplitudes and latencies of these peaks to be strongly correlated. This was the case for EP1 and EP2, with an amplitude correlation coefficient $\left(R^{2}\right)$ of $0.48(p<0.00001)$.

\section{Pyramidal tract activation produces a very short-latency cortical potential}

Because our primary goal was to identify EPs corresponding unambiguously to antidromic hyperdirect activation, we had to 


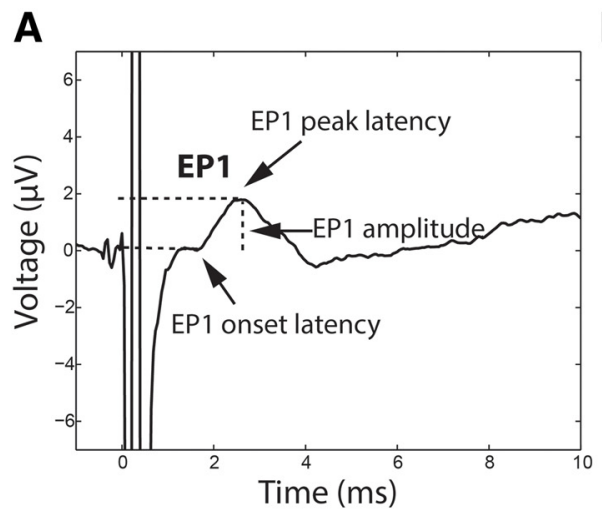

B

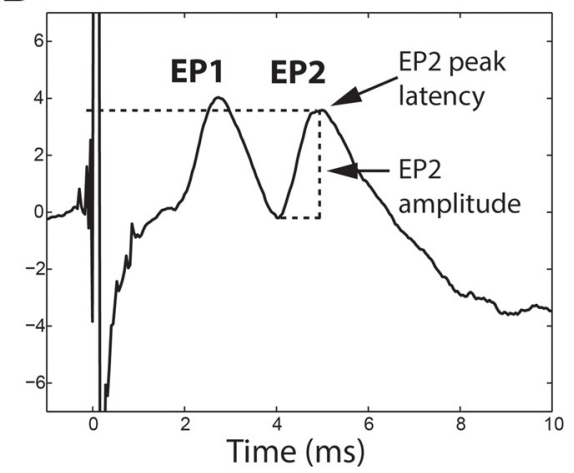

C

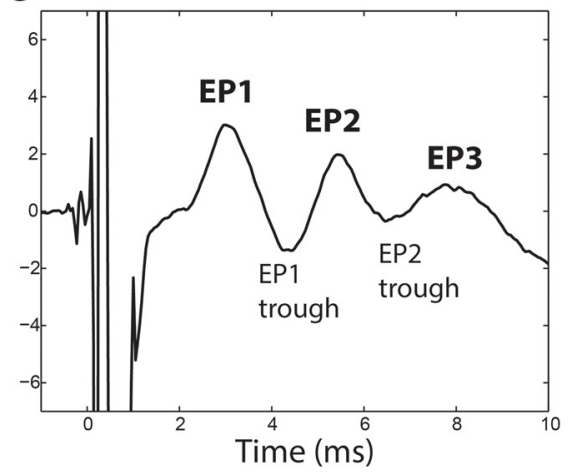

D

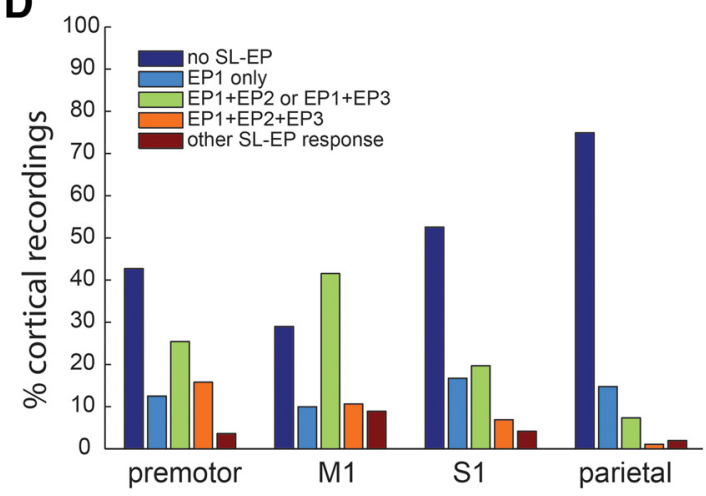

Figure 2. Morphology of short-latency EPs evoked by STN DBS. A-C, The short-latency EP (SL-EP) contained 1-3 peaks (examples from Patients 4, 1, and 5). The first short-latency peak was defined as EP1, and the following trough as EP1 trough. EP1 peak amplitude was defined with respect to the preceding baseline. The subsequent peaks were defined as EP2 and EP3 with peak amplitude defined by the preceding trough. $\boldsymbol{D}$, The number of short-latency EP peaks varied by cortical location and was the highest in M1 (data from all STN patients).
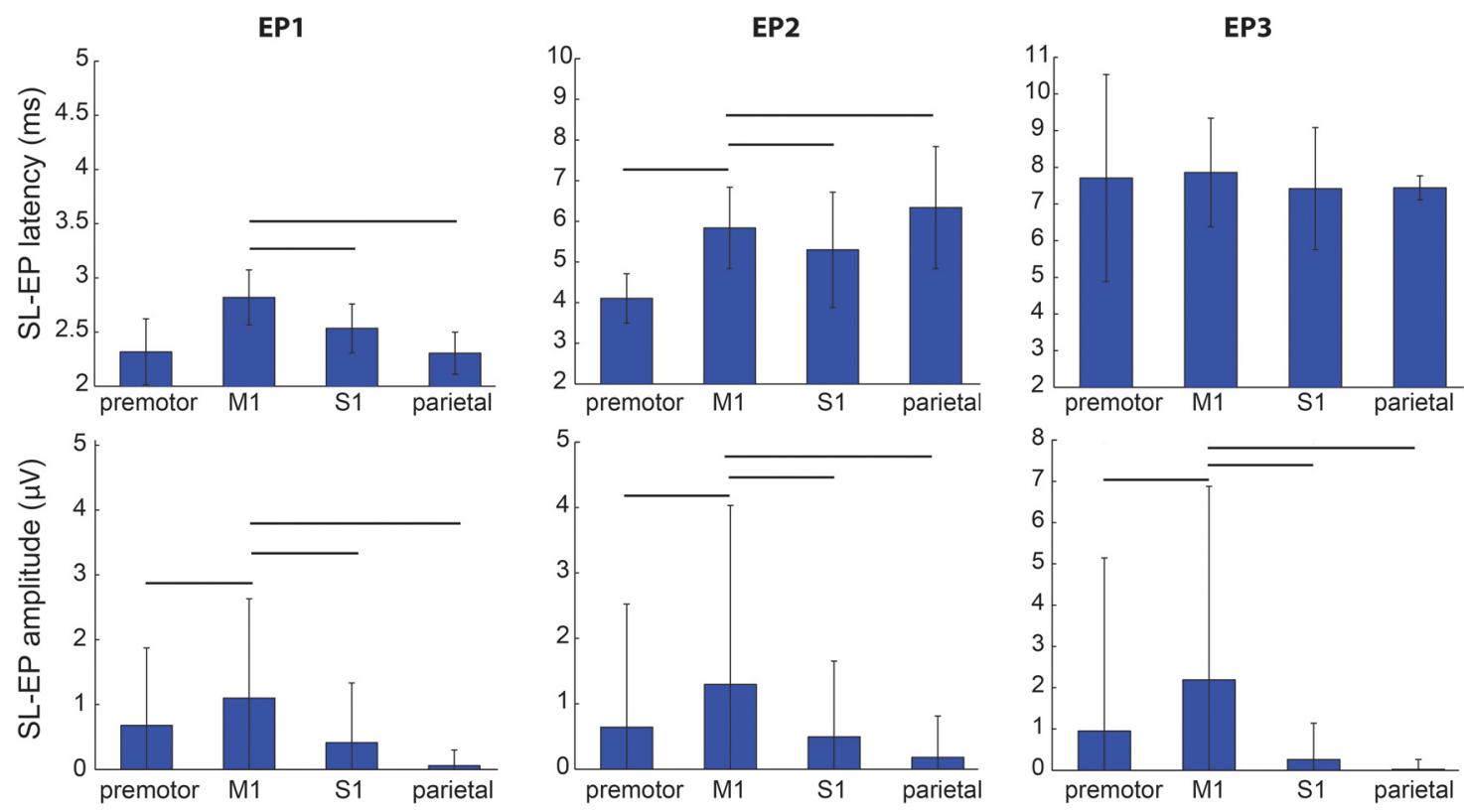

Figure 3. Topographic variation in latencies and amplitudes of short-latency (2-10 ms) EPs. Latencies (top row) and amplitudes (bottom row) of EPs by recording region (mean \pm SD; data from all 7 STN patients). Lines indicate statistically significant differences between M1 and other cortical regions (paired $t$ test, significant $p$ value 0.003 after Bonferroni correction).

consider the possibility that the spread of DBS current outside of the STN could activate the corticospinal/corticobulbar (CSB) tract, producing a very fast $\mathrm{EP}$ that could be confused with antidromic hyperdirect activation related to stimulation within the STN. Furthermore, the hyperdirect pathway may be formed in part by collaterals from the same pyramidal projection neurons that form the CSB tract (Kita and Kita, 2012), which would complicate the interpretation of the observed cortical potentials. We propose criteria to differentiate between these possibilities (CSB vs hyperdirect activation). Stimulation induced activation of CSB pyramidal fibers in the internal capsule should: (1) produce a slightly shorter-latency cortical EP compared with hyperdirect 
A
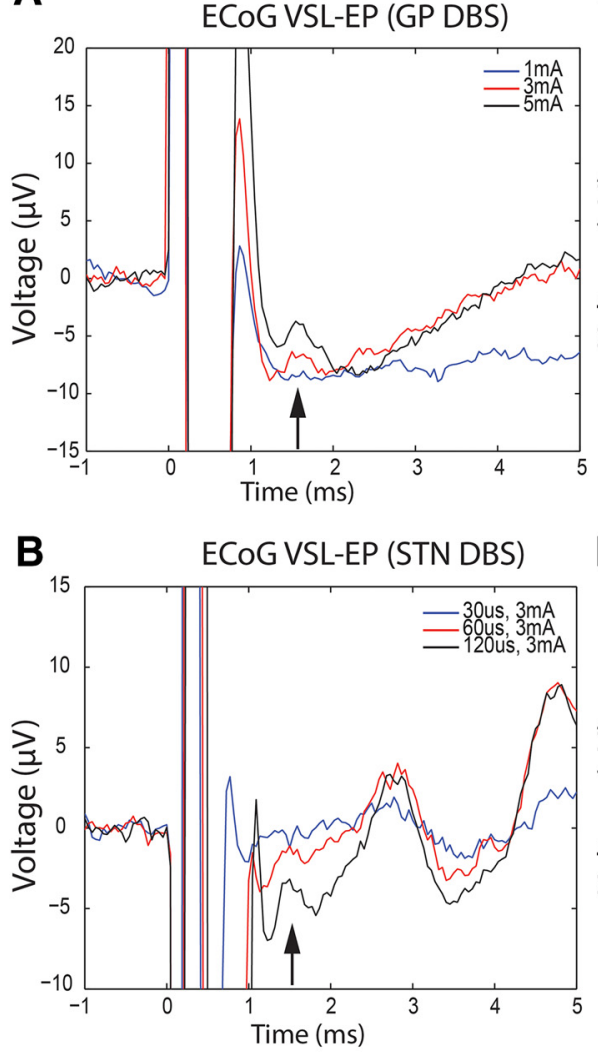

C

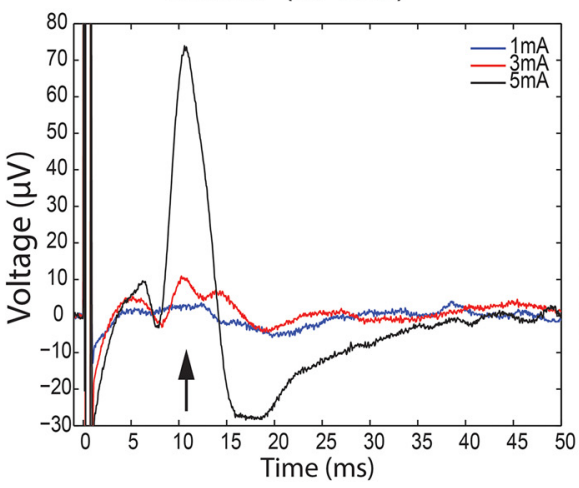

E
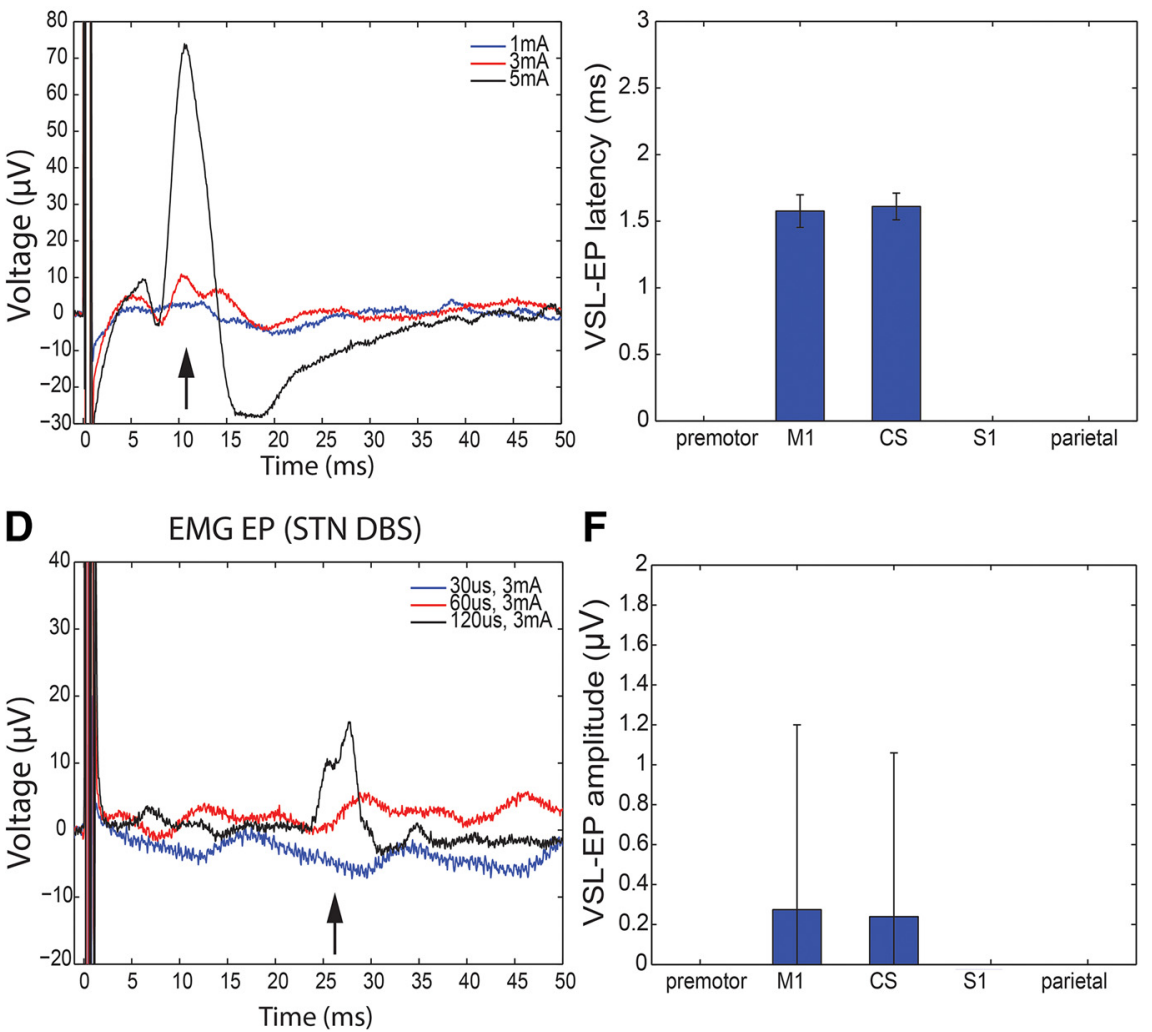

$\mathbf{F}$

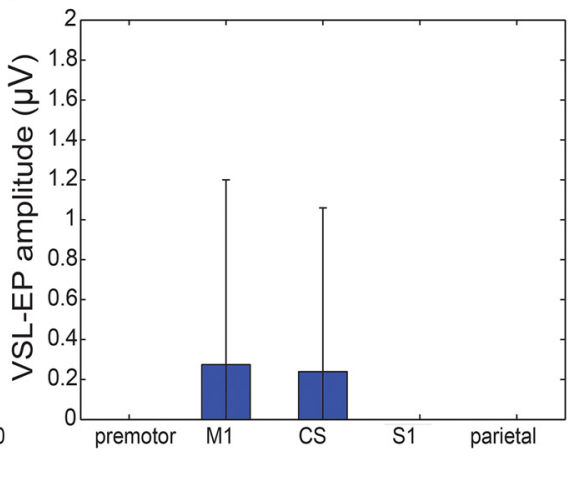

Figure 4. Very short-latency EPs (VSL-EP) can be evoked by GP or STN stimulation and are associated with an EMG response, reflecting current spread to the pyramidal tract. Very short-latency EPs (upgoing at $\sim 1.5 \mathrm{~ms}$ ) were present in M1 channels during high-intensity GP DBS ( $\boldsymbol{A}$, red and black traces at high amplitudes; Patient $10, \boldsymbol{C}+0-60 \mu$ s pulse width, $10 \mathrm{~Hz}$ ) and STN DBS ( $\boldsymbol{B}$, black trace at high pulse width; Patient $6, C+1-3 \mathrm{~mA}, 10 \mathrm{~Hz}$ ). They occurred together with EMG EPs consistent with activation of corticobulbar $(\boldsymbol{C}$, genioglossus muscle, red and black traces; latency 10.5 $\mathrm{ms}$ ) and corticospinal tracts ( $\boldsymbol{D}$, first dorsal interosseous muscle, black trace; latency $28 \mathrm{~ms}$ ). Low-intensity DBS (blue traces and red trace in bottom panels) did not evoke ECoG or EMG response. The ECOG and EMG traces were recorded at the same time and are shown without smoothing. $\boldsymbol{A}-\boldsymbol{D}$, Single trial examples. $\boldsymbol{E}$, $\boldsymbol{F}$, Very short-latency EPs were present only in channels overlying the M1 and central sulcus (CS). There was no statistical difference in EP latency and amplitude between these two regions (mean \pm SD for 3 STN and 1 GP patient).

fibers due to the very large diameter of pyramidal tract axons; (2) be uniquely associated with muscle activation as well as a cortical EP; (3) be producible by both STN and GP stimulation (because both structures are in close proximity to internal capsule, whereas only STN is thought to have hyperdirect input); and (4) have a different cortical topography from hyperdirect activation because the former originates almost exclusively from primary motor area while the latter is thought to originate from widespread areas of frontal cortex.

We did detect a very short latency cortical potential with mean peak latency of $1.5 \pm 0.1 \mathrm{~ms}$ from the start of the stimulation pulse, which met our criteria for pyramidal tract activation and was distinct from a slightly longer latency, putative hyperdirect EP. This putative pyramidal tract EP was detected in 4/10 patients (3 STN, $1 \mathrm{GP}$; Fig. 4A,B). As expected, these very short-latency cortical potentials generally were associated with muscle activation. EMG EPs were identified in three patients who had very short latency cortical EPs (1 patient did not have EMG recordings available) but not in the four patients who did not have very short latency cortical EPs (2 patients did not have EMG recordings). In general, the same stimulation settings that evoked EMG response also evoked the very early cortical response, and they were most often high amplitude or wide pulse width monopolar settings (Fig. 4C,D). Among the three patients who had both EMG and very early cortical responses, there were a total of 20 stimulation settings that evoked EMG and/or very early cortical response: 13 evoked both, 6 evoked EMG only, and 1 evoked cortical only.
Finally, these very short-latency EPs were only present in 1-2 cortical channels per patient (those spanning the posterior M1 or the central sulcus), whereas EPs corresponding to putative hyperdirect activation were detectable over a wider cortical area (Figs. $3,4 E, F)$.

\section{Long-latency cortical EPs may reflect orthodromic basal ganglia activation}

Long-latency cortical EPs could arise from orthodromic activation of polysynaptic basal ganglia-thalamo-cortical pathways. These should be evoked by both STN and GP DBS, but presumably at slightly different latencies corresponding to the synaptic delay introduced by the STN-GP projections. We found that both STN and GP stimulation evoked long-latency (10-100 ms) EPs (Fig. 5). The general waveform shape in M1 was similar for all STN and GP patients (Fig. $5 A, B$ ).

The STN DBS cortical response in M1 was characterized by previously described short-latency EPs followed by a trough (T1) at $20 \pm 8 \mathrm{~ms}$, then a peak (P1) at $38 \pm 11 \mathrm{~ms}$, a trough (T2) at $56 \pm 15 \mathrm{~ms}$ and a peak (P2) at $71 \pm 16 \mathrm{~ms}$ (mean \pm SD for all STN patients). The GP DBS resulted in a peak (P1) at $19 \pm 3 \mathrm{~ms}$, then a trough (T2) at $29 \pm 4 \mathrm{~ms}$ followed by a peak (P2) at $44 \pm 9 \mathrm{~ms}$ (mean \pm SD for all GP patients). In two GP patients, there was also an earlier trough (T1) at $10 \pm 2 \mathrm{~ms}$. Thus, there was a similarity in cortical responses evoked by the two targets, with the STN lagging GP by 10-20 ms. Comparing GP evoked versus STN evoked latencies across different patients can only provide an 
A
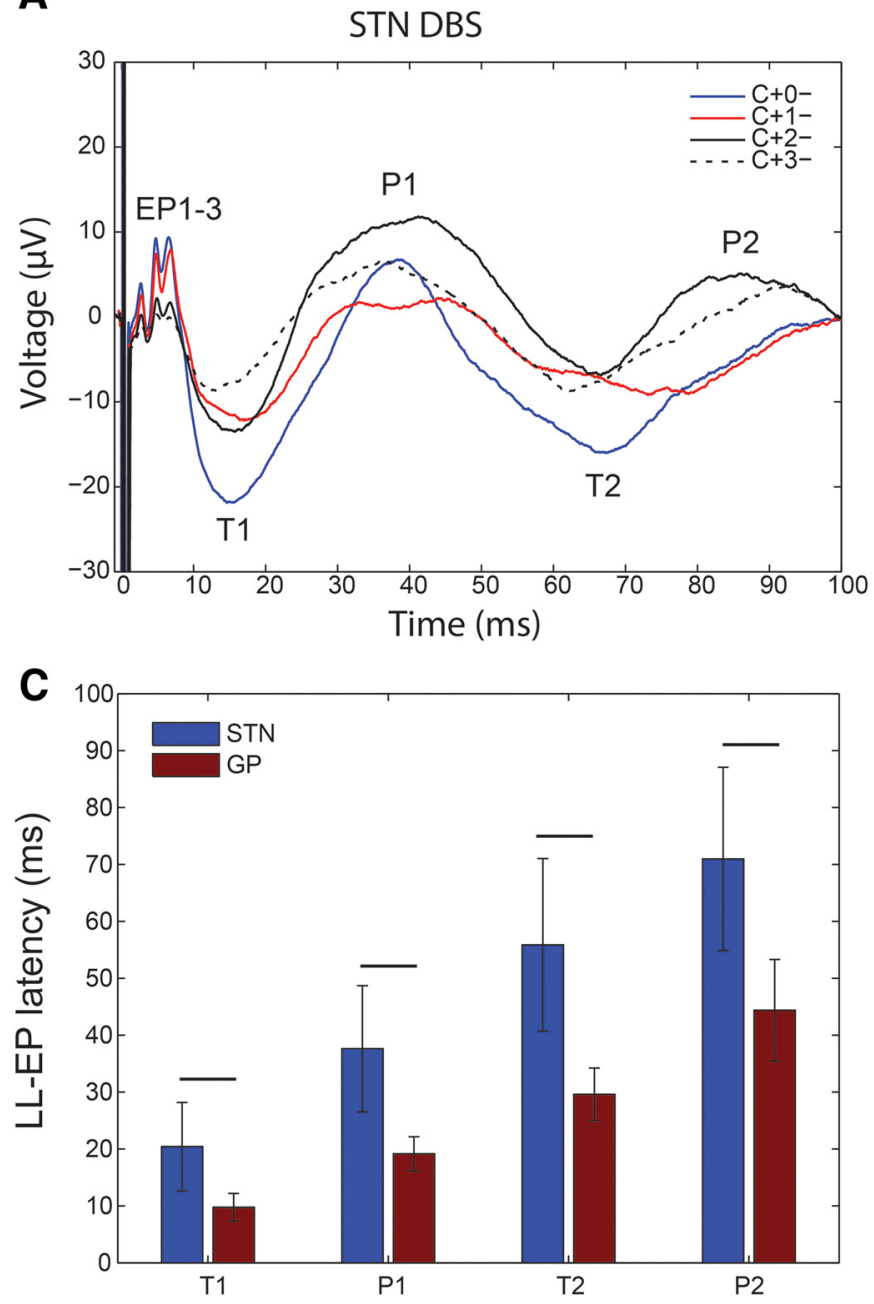

B
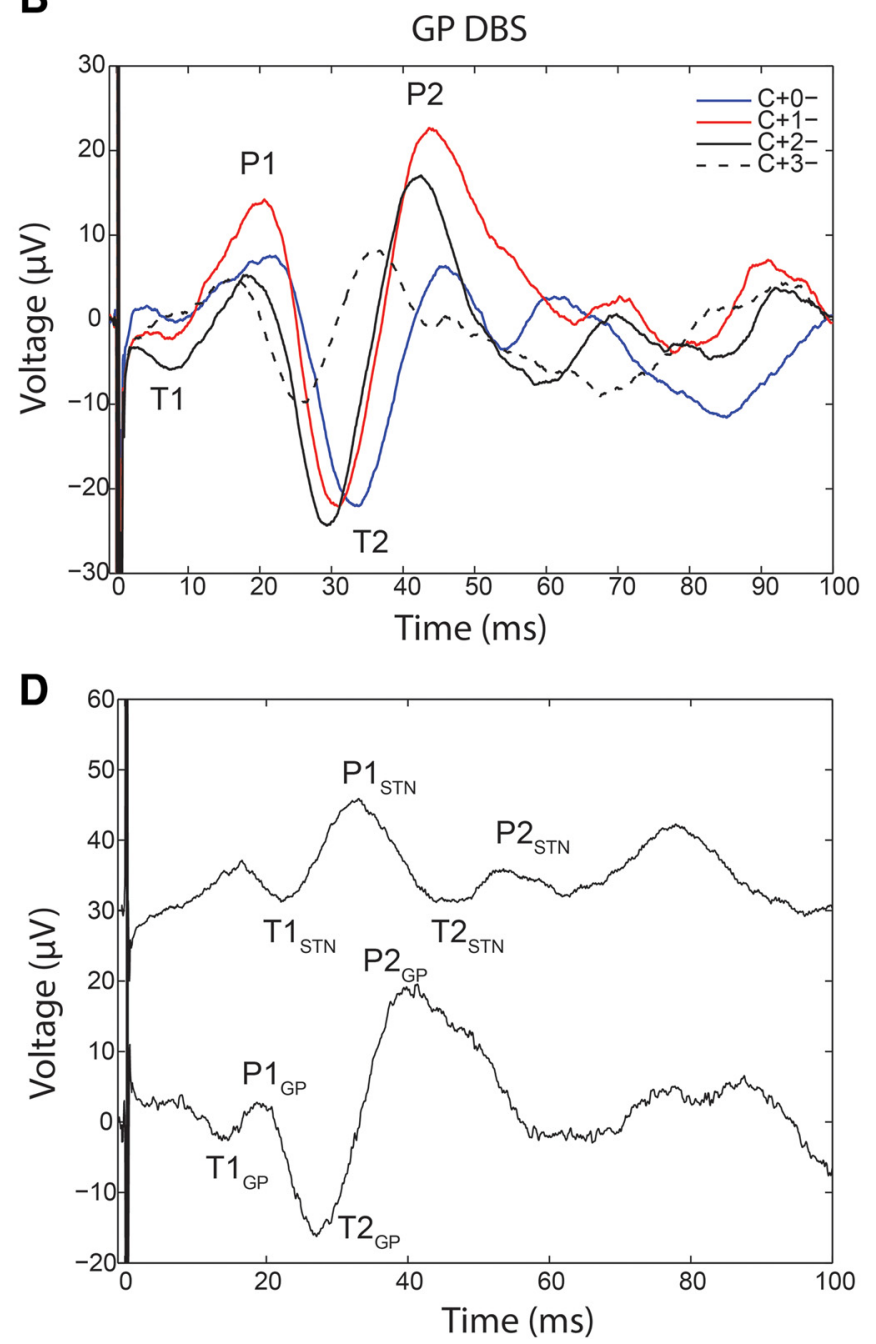

Figure 5. Waveforms and latencies of late occurring EPs are consistent with orthodromic activation. $\boldsymbol{A}, \boldsymbol{B}$, Typical appearance of long-latency EPs (LL-EP) in M1 from STN (A; Patient 6) and GP ( $\boldsymbol{B}$; Patient 10) using different DBS contacts (monopolar, $3 \mathrm{~mA}, 60 \mu \mathrm{s}, 10 \mathrm{~Hz}$ ). The most consistent peaks and troughs are labeled T1, P1, T2, and P2. EP1-3 refers to short-latency peaks and troughs evoked by STN DBS only. C, Comparison of latencies of long latency M1 potentials evoked by STN or GP (mean \pm SD for all patients). $D$, Direct comparison of M1 cortical potentials evoked by STN (top) and GP DBS (bottom) in a patient with both targets implanted. Stimulation settings: STN DBS 2-1+, $3 \mathrm{~mA}, 60 \mu \mathrm{s}, 2 \mathrm{~Hz}$; GPi DBS 0-1+, $3.2 \mathrm{~mA}, 60 \mu \mathrm{S}, 2 \mathrm{~Hz}$. A, B, D, Single trial examples.

approximate measure of the STN-GP synaptic delay given differences in brain morphology between subjects. However, in one patient who had both STN and GP electrodes, similar latencies were measured (8 ms lag for T1, $14 \mathrm{~ms}$ lag for P1, 19 ms lag for T2, and $13 \mathrm{~ms}$ lag for P2; Fig. 5D). The calculated lag may be too long to arise from a monosynaptic STN-GPi transmission and could include re-entrant loops between STN-GPe-GPi.

\section{The influence of DBS parameters on short latency cortical potentials}

During clinical DBS programming, stimulation settings are systematically changed and therapeutic benefit or side effects noted, but without clear understanding of how these changes affect underlying neural activation. Therefore, we examined the relationship between short latency cortical potentials and DBS parameter changes. Stimulation settings that we altered included: location of negative contact (cathode), amplitude, pulse width, configuration (monopolar vs bipolar), polarity (cathode/anode arrangement), and frequency. For comparative analysis described below all other stimulation parameters were held constant (Figs. 6, 7; Table 2).
The larger DBS amplitude evoked larger EPs, but peak latency was unchanged, except for EP3 where lowest stimulation amplitude resulted in $1 \mathrm{~ms}$ slower latency compared with highest (Figs. $6 A, 7 A)$. EP amplitude was significantly different between four stimulation contacts, which was due to amplitude being larger at the two most ventral contacts (Figs. $6 B, 7 B$ ). The peak latency did not differ between the contacts except for EP3, where the most ventral contact resulted in $\sim 1 \mathrm{~ms}$ faster potential compared with the two dorsal contacts. The size of the EP could be further modulated by changing the stimulation pulse width so that longer pulse widths resulted in larger EPs, but peak latency was again unchanged (Figs. 6C, 7C). High-frequency stimulation evoked responses of similar amplitude and latency as low-frequency stimulation (Figs. $6 F, 7 D$ ), arguing against potentiation or depotentiation of the EP amplitude by preceding pulse.

DBS studies often use bipolar instead of monopolar stimulation to reduce the stimulation artifact. It has been proposed that bipolar stimulation amplitude should be increased by 30\% to achieve similar volume of activation as monopolar stimulation (MacKinnon et al., 2005; Eusebio et al., 2009). We tested this assumption directly by comparing the size of EP1 during mono- 
A Stimulation amplitude

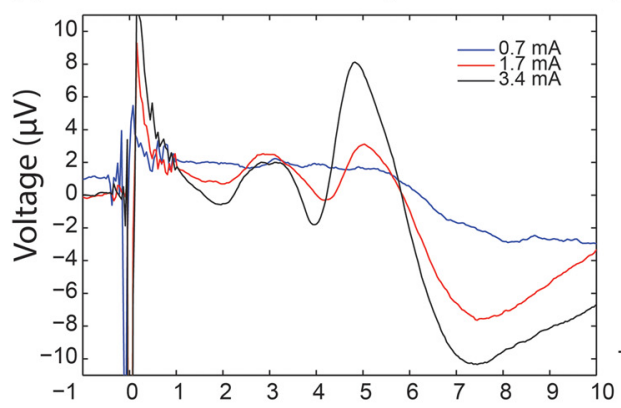

D

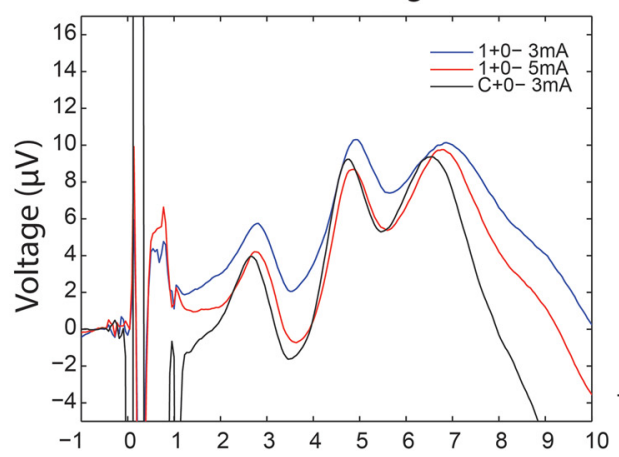

B Stimulation contact

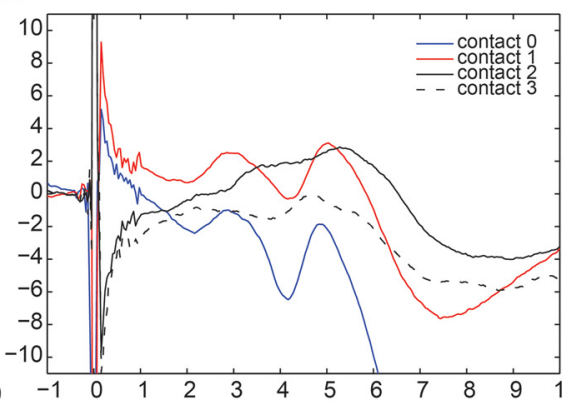

E

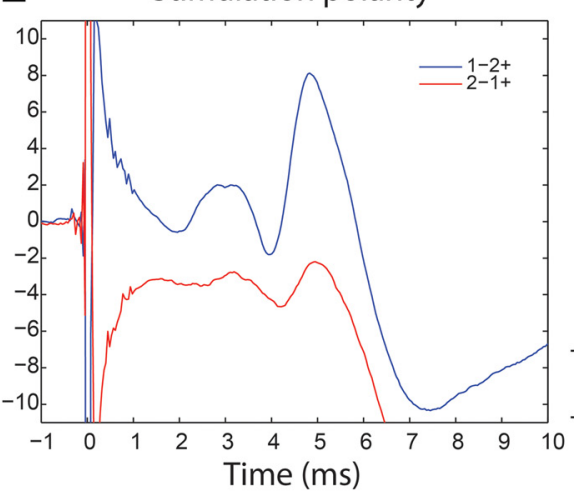

C Stimulation pulse width

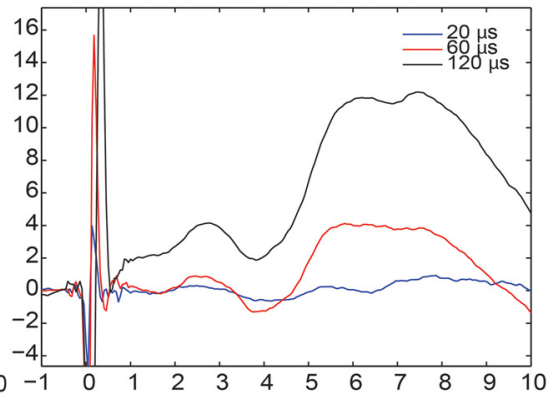

F Stimulation frequency

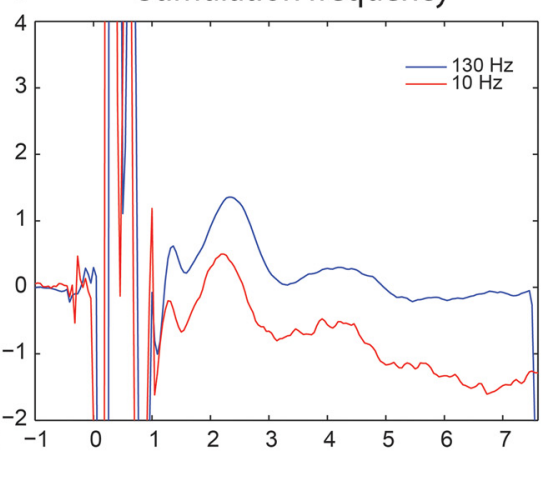

Figure 6. Effects of changes in stimulation parameters on waveforms of short-latency EPs. Single trial examples of short-latency EP variation with changes in $\boldsymbol{A}$, amplitude (Patient $1,1-2+60$ $\mu \mathrm{s}) ; \boldsymbol{B}$, negative contact choice (Patient 1, $1.7 \mathrm{~mA}, 60 \mu \mathrm{s}$ ); $\boldsymbol{C}$, pulse width (Patient 4,0-1 $+3 \mathrm{~mA}$ ); $\boldsymbol{D}$, monopolar versus bipolar configuration (Patient 6, $60 \mu \mathrm{s}$ ). Bipolar stimulation at $5 \mathrm{~mA}$ is similar to monopolar stimulation at $3 \mathrm{~mA} ; \boldsymbol{E}$, contact polarity (Patient 1, $3.4 \mathrm{~mA}, 60 \mu \mathrm{s}$ ); and $\boldsymbol{F}$, stimulation frequency (Patient 6,2+1-3 mA, $60 \mu \mathrm{s}$ ). EP amplitude, latency, and number of peaks did not change with high- versus low-frequency stimulation.

polar versus bipolar stimulation, and calculating bipolar amplitude necessary to produce the same size EP as $1 \mathrm{~mA}$ monopolar stimulation. This was $1.9 \mathrm{~mA}$ in Patient 4 and $1.8 \mathrm{~mA}$ in Patient 6, thus bipolar amplitude had to be increased by at least $80 \%$ to achieve the same volume of activation for putative hyperdirect axons (Fig. 6D). In Patient 5 who also had the longest EP1 latency, bipolar stimulation resulted in much smaller EP1 than monopolar so that comparable bipolar amplitude was $3.8 \mathrm{~mA}(280 \%$ increase).

In prior efforts to identify short-latency EPs using scalp EEG, investigators have subtracted artifacts generated with opposite polarity stimulation, to isolate short-latency EPs that would otherwise be obscured by the artifact (Baker et al., 2002; Walker et al., 2012). However this method assumes that the DBS effect is the same regardless of the order of cathode and anode (e.g., 1-2+ vs $2-1+)$. We tested this assumption by comparing EP1 responses for all stimulation setting pairs of opposite polarity (with other parameters held constant), and found they varied greatly (Fig. $6 E)$. Specifically, the amplitude of EP1 differed by more than $\pm 25 \%$ between paired settings of opposite polarity in 378 (82\%) waveforms where EP1 was detected.

\section{Clinical correlation}

Finally, we assessed whether the amplitude of cortical responses evoked by specific DBS contact correlated with its therapeutic effectiveness. We could not determine therapeutic benefit for multiple stimulation settings in the operating room due to time constraints. We therefore reviewed patients' clinical records to determine which DBS contact(s) were used for chronic stimulation (settings were optimized using standard clinical program- ming methods). In all seven STN patients, the DBS contact producing the largest EP1 in M1 intraoperatively was the same as $(5 / 7)$ or adjacent to $(2 / 7)$ the contact used clinically (Fig. 8). In two patients the initial clinical contact was changed after several programming sessions and their final contact corresponded to the one with the largest EP1 intraoperatively (Patient 2 went from contact 2 to contact 0 ; Patient 5 went from contact 2 to contact 3 then contact 4). Patient 7 had a suboptimally therapeutic STN lead, which was replaced by GP lead (hence the opportunity to record from both leads), and interestingly he had very small short-latency EPs evoked by STN, present at only two stimulation settings tested. The other short-latency EPs (EP2 and EP3) and long-latency EPs (T1, P1, T2, P2) were not as predicative of the final therapeutic contact, either at M1 or other locations.

\section{Discussion}

In patients with Parkinson's disease undergoing insertion of DBS leads in the awake state, we used temporary subdural recording strips to characterize cortical potentials evoked by STN and GP stimulation. We show that STN stimulation results in multiple short-latency (2-10 ms) EPs consistent with activation of a corticosubthalamic hyperdirect pathway, originating from primary motor, premotor, and sensory areas, whereas no such response was present during GP stimulation. The amplitude of the early response (peak at $2.8 \mathrm{~ms}$ ) in $\mathrm{M} 1$ was predictive of the final therapeutic stimulation contact. The putative hyperdirect potentials were distinct from very short-latency EPs (at $1.5 \mathrm{~ms}$ peak latency) spatially localized to M1 and related to corticospinal and corticobulbar tract activation observed on EMG. Both STN and GP DBS 


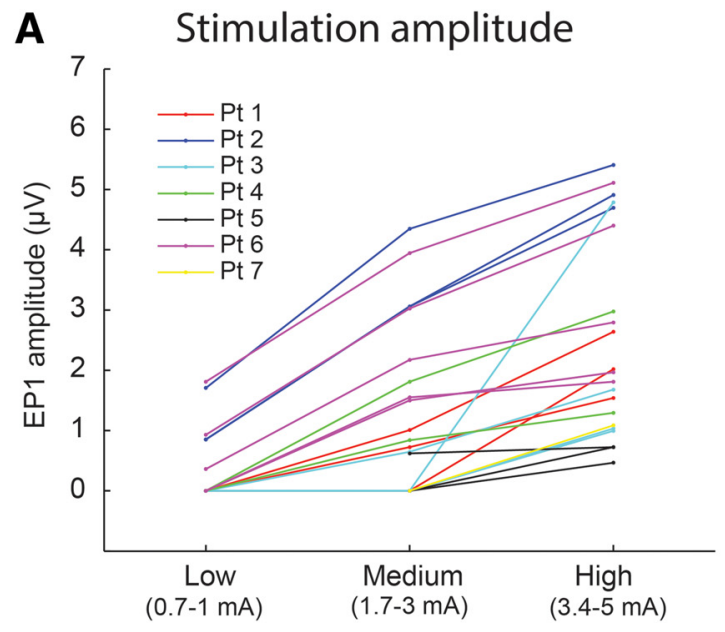

\section{Stimulation pulse width}

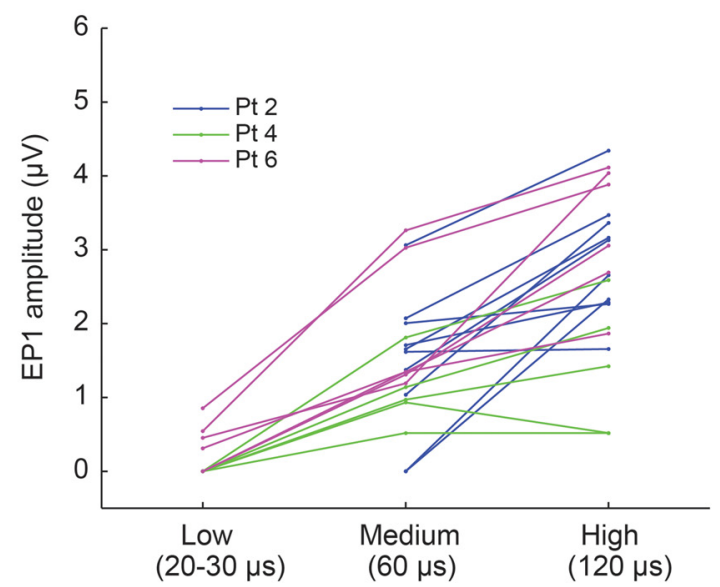

\section{B Stimulation contact}

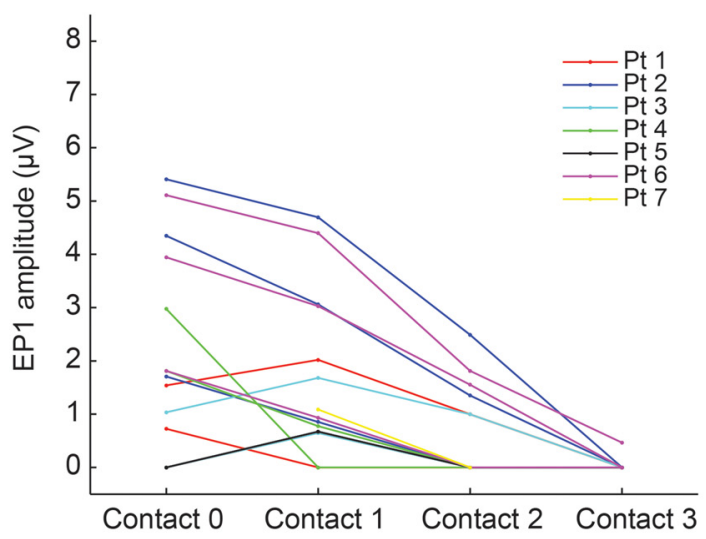

D Stimulation frequency

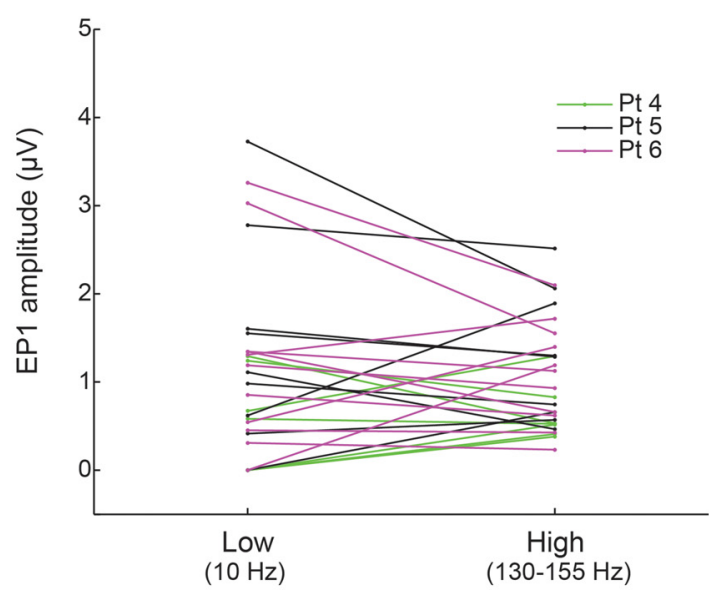

Figure 7. Quantitative analysis of the effects of changes in stimulation parameters on EP1 amplitude. $A, E P 1$ amplitude at low $(0.7-1 \mathrm{~mA})$, medium $(1.7-3 \mathrm{~mA})$, and high ( $3.4-5 \mathrm{~mA})$ stimulation current amplitude. Lines are connecting comparative trials where all other stimulation parameters were held constant. $B$, EP1 amplitude at four stimulation contacts (cathodes). Contact 0 was in ventral STN, contact 2 in dorsal STN, and contact 3 in zona incerta (except Patients 1 and 2 where contact 2 was also outside STN). For Patient 5 , contacts $2-5$ were plotted. C, EP1 amplitude at low $(20-30 \mu \mathrm{s})$, medium $(60 \mu \mathrm{s})$, and high $(120 \mu \mathrm{s})$ stimulation pulse width. $\boldsymbol{D}$, EP1 amplitude at low $(10 \mathrm{~Hz})$ and high $(130-155 \mathrm{~Hz})$ stimulation frequency. $A, B$, Data from only one M1 channel shown for clarity. C, D, Only three patients had comparative trials and data from only M1 channels shown for clarity. Accompanying statistics are in Table 2.

Table 2. The effect of STN stimulation parameter change on amplitude and latency of cortical short-latency EPs (group comparison statistics)

\begin{tabular}{|c|c|c|c|c|c|c|}
\hline & \multicolumn{2}{|l|}{ EP1 } & \multicolumn{2}{|l|}{ EP2 } & \multicolumn{2}{|l|}{ EP3 } \\
\hline & Amplitude & Peak latency & Amplitude & Peak latency & Amplitude & Peak latency \\
\hline $\begin{array}{l}\text { DBS amplitude } \\
\text { (low, mid, high) }\end{array}$ & $F_{(2,1069)}=255.7 ; p<10^{-6}$ & $F_{(2,685)}=1.04 ; p=0.35$ & $F_{(2,1029)}=132.66 ; p<10^{-6}$ & $F_{(2,586)}=1.06 ; p=0.35$ & $F_{(2,717)}=38.82 ; p<10^{-6}$ & $F_{(2,467)}=8.38 ; p=0.0003$ \\
\hline $\begin{array}{l}\text { DBS negative } \\
\quad \text { contact }(0,1,2,3)\end{array}$ & $F_{(3,613)}=11.22 ; p<10^{-6}$ & $F_{(3,602)}=2.82 ; p=0.04^{b}$ & $F_{(3,545)}=3.22 ; p=0.02$ & $F_{(3,529)}=1.36 ; p=0.26$ & $F_{(3,455)}=0.01 ; p=0.99$ & $F_{(3,444)}=4.63 ; p=0.003$ \\
\hline $\begin{array}{l}\text { DBS pulse width }{ }^{a} \\
\quad \text { (low, mid, high) }\end{array}$ & $F_{(2,192)}=50.28 ; p<10^{-6}$ & $F_{(2,129)}=1.37 ; p=0.26$ & $F_{(2,147)}=76.98 ; p<10^{-6}$ & $F_{(2,89)}=1.22 ; p=0.30$ & $F_{(2,141)}=9.11 ; p=0.0002$ & $F_{(2,94)}=0.08 ; p=0.93$ \\
\hline $\begin{array}{r}\text { DBS frequency }^{a} \\
\text { (low, high) }\end{array}$ & $T_{(114)}=0.0638 ; p=0.95$ & $T_{(89)}=-1.3028 ; p=0.19$ & $T_{(78)}=1.9195 ; p=0.06$ & $T_{(53)}=1.8959 ; p=0.06$ & n.a. & n.a. \\
\hline
\end{tabular}

Data from all cortical locations were used for analysis.

${ }^{a}$ Only three patients had comparative trials of pulse width and high-frequency.

${ }^{b}$ No significant differences on post hoc testing.

n.a., Not applicable because high-frequency stimulation interpulse interval is too short to observe EP3.

evoked long-latency cortical potentials consistent with activation of an orthodromic multisynaptic pathway to the cortex.

\section{Corticosubthalamic activation revealed by short-latency EPs} Unequivocal physiological evidence for a hyperdirect pathway in humans has been elusive. There have been several prior studies of cortical potential evoked by basal ganglia stimulation using scalp EEG as the recording technique, during stimulation in STN (Ashby et al., 2001; Baker et al., 2002; MacKinnon et al., 2005; Eusebio et al., 2009; Kuriakose et al., 2010; Walker et al., 2012) or GP (Tisch et al., 2008; Bhanpuri et al., 2014). However, in most of these, the stimulation artifact was too long and sampling fre- 

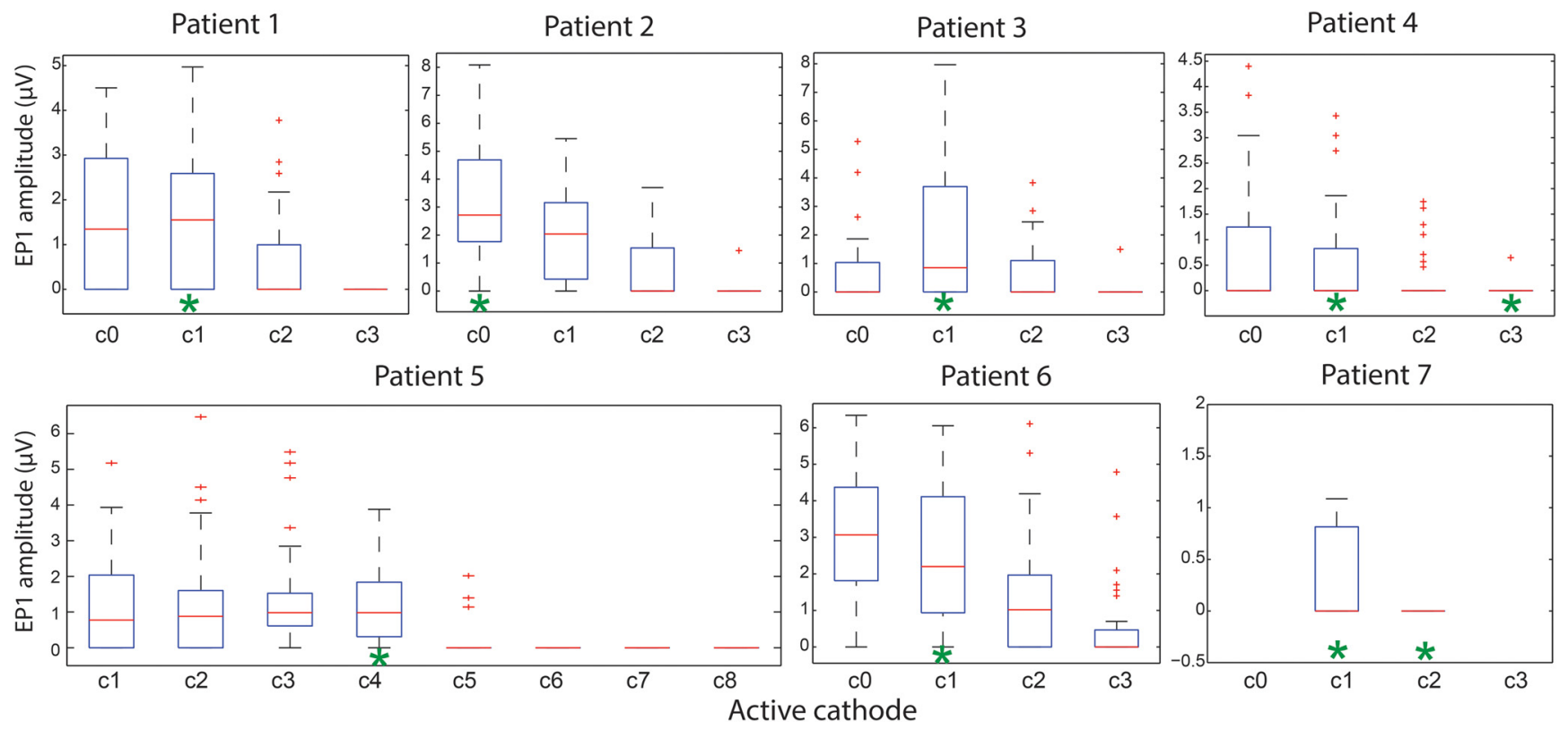

Figure 8. Relationship between amplitude of the short-latency EP1 in M1 and eventual active contact choice for optimal motor improvement. EP1 amplitudes (from all contacts overlying M1) are grouped by negative (cathodal) stimulation contact for each STN patient. Cathodal contacts selected by a neurologist for chronic use after extensive empirical programming are indicated by green asterisks. Boxplot central mark indicates the median, and the bottom and top edges of the box indicate the 25th and 75th percentiles, respectively. The whiskers extend to the most extreme data points not considered outliers, and the outliers are plotted individually.

quency too low to observe cortical activation at latencies $<2 \mathrm{~ms}$ due to both technical issues and biophysical limitations of extracranial recordings. Despite these limitations, several EEG investigators directly observed early EPs at 2-3 ms (Ashby et al., 2001; Kuriakose et al., 2010), but their analysis primarily focused on long-latency potentials.

Utilizing invasive cortical recording, here we demonstrate short latency $(2.5-8 \mathrm{~ms})$ potentials that are very likely to represent antidromic hyperdirect activation, based on several criteria: (1) they are not evoked by GP stimulation (which has not been shown to have hyperdirect cortical innervation), (2) they are distinct from longer latency EPs likely related to orthodromic activation (via GP and thalamus), and (3) they are clearly distinguishable from both stimulation artifact and from very short-latency EPs evoked by current spread to adjacent pyramidal fibers. The very short-latency EP at $1.5 \mathrm{~ms}$ evoked by high-intensity STN or GP stimulation is consistent with the known corticospinal conduction velocity of $40 \mathrm{~m} / \mathrm{s}$ (Ashby et al., 1998) and approximate distance from M1 to internal capsule of $6 \mathrm{~cm}$. In addition, we show that the cortical localization of the very short-latency EP is restricted to M1, whereas that of the EPs proposed to arise from hyperdirect activation is more widespread.

The multiple short latency (2-10 ms) peaks usually occurred together. These could represent activations of different hyperdirect corticofugal bundles, which contain axons of different diameters. Rodent histological tracings have shown that STN collaterals arise from thin-to-medium-sized axons but not from thick axons (Kita and Kita, 2012). As expected, hyperdirect conduction velocities are slower than the large-axon corticospinal tract and based on our findings range from 6 to $24 \mathrm{~m} / \mathrm{s}$. Alternatively, the later peaks could represent corticocortical activation through synaptic transmission at collaterals of antidromically activated axons as seen in rats (Li et al., 2007), and supported by a recent modeling study (Kumaravelu et al., 2018). Finally, the existence of monosynaptic projections from the STN to cortex has been reported, and activation of this monosynaptic pathway could also account for the later peaks (Degos et al., 2008).

\section{Topography of cortical innervation of the basal ganglia}

The corticosubthalamic hyperdirect pathway in nonhuman primates originates from the frontal cortex, anterior to the central sulcus (Monakow et al., 1978; Nambu et al., 1996). Direct cortical projections from the sensory cortex into STN have not been described on histological tracings in primates (Smith et al., 2001). Here we show that antidromic activation readily occurs in the primary sensory cortex and to a lesser extent in the more posterior parietal regions, which raises the possibility of hyperdirect subthalamic projections from these cortical areas. This possibility is also supported by single-cell cortical recordings in nonhuman primates demonstrating antidromic invasion of sensory cortex at 2-5 ms latencies following STN stimulation (Gale, 2004). This finding may have implications for sensory symptoms in Parkinson's disease and alterations in somatosensory processing with DBS (Jobst et al., 1997; Maruo et al., 2011). Although there is some evidence for a "hyperdirect" cortical projection to the pallidum based on histological studies in rodents (Naito and Kita, 1994) and nonhuman primates (Smith and Wichmann, 2015), and a tractography study in humans (Milardi et al., 2015), neither we nor nonhuman primate study (Devergnas and Wichmann, 2011) found short-latency EPs from pallidal stimulation. This argues against the existence of direct cortical projections into the motor pallidum in primates.

\section{Orthodromic activation of cortex via basal ganglia output nuclei and mechanisms of DBS}

The long latency cortical responses observed here are likely to result from orthodromic activation of the basal ganglia motor pathway involving the STN, GPi/GPe, thalamus, and cortex (Hashimoto et al., 2003). They are expected to occur with both 
STN and GP DBS because STN has a strong monosynaptic projection to GP in primates (Smith et al., 1994). The overall pattern of the cortical responses from the two DBS targets was similar, but STN peaks and troughs lagged behind GP by $10-20 \mathrm{~ms}$, which would account for additional synaptic connections since STN is further upstream in the motor loop. In previous EEG studies of long-latency EPs, STN DBS most consistently resulted in initial $\sim 20 \mathrm{~ms}$ response (MacKinnon et al., 2005; Eusebio et al., 2009; Kuriakose et al., 2010), which matches our T1 response at $21 \mathrm{~ms}$. GP DBS in EEG studies of dystonia patients resulted in initial EPs at 20-28 ms, which is similar to our P1 and T2 responses at 19 and $29 \mathrm{~ms}$, respectively (Tisch et al., 2008; Bhanpuri et al., 2014). However, earlier EP at $10 \mathrm{~ms}$ has also been reported (Ni et al., 2018) comparable with the T1 response seen in two of our patients.

Although we used low-frequency stimulation to measure EP amplitudes in this study, similar EP responses were observed at high, clinically-relevant frequencies (Fig. $6 F$ ). There is considerable rodent evidence that antidromic hyperdirect activation produces a therapeutic effect (Dejean et al., 2009; Gradinaru et al., 2009; Li et al., 2012; Sanders and Jaeger, 2016). However, it is unlikely that hyperdirect corticosubthalamic activation is the unique therapeutic mechanism for basal ganglia DBS, as this would not explain the remarkable similarity of the clinical effects of STN and GP DBS in Parkinson's disease (Mansouri et al., 2018) and in related disorders such as isolated dystonia (Ostrem et al., 2017).

\section{Physiological predictors of therapeutic response}

Identification of an objective physiological signal that predicts therapeutic response could improve our ability to program DBS devices in a more targeted fashion. Here, we demonstrate a close match between intraoperative DBS contact with the largest early cortical response and the contact that was eventually found to be clinically optimal based on standard empirical (trial-and-error) programming.

Several previous EEG studies have attempted to use cortical EPs to identify best therapeutic DBS contacts. This approach was successful in GP DBS in patients with dystonia (Tisch et al., 2008; Bhanpuri et al., 2014), but inconsistent for STN DBS in Parkinson's disease (MacKinnon et al., 2005; Kuriakose et al., 2010). In both GP and STN studies, prior investigators focused on medium latency responses at $\sim 20 \mathrm{~ms}$. Our results indicate that correlation with therapeutic effectiveness in the STN needs to be investigated at earlier latencies that correspond to hyperdirect activation. Of note, activation of the hyperdirect pathway could be a surrogate marker of clinical response while the true therapeutic target population, such as neurons in the sensorimotor STN region and their efferent projections, could be optimally activated by the same settings.

An alternative approach to objective physiological confirmation of effective therapeutic stimulation is to use the amplitude of beta-band oscillatory activity in the STN LFP, because the region of highest beta-band activity predicts the therapeutic DBS contact (Zaidel et al., 2010), and reduction in beta band activity induced by DBS correlates with clinical improvement (Kühn et al., 2008). A potential advantage of using cortical recordings over STN LFP recordings is that cortical EPs could also guide the avoidance of adverse effects (by minimizing very short-latency EPs from pyramidal tract activation) and inform on other stimulation parameters such as the amplitude and pulse width to maximize hyperdirect pathway recruitment. A disadvantage is the need for chronic cortical sensing, but such sensing capability is now available using a totally implantable bidirectional neural interfaces (Swann et al., 2018).

\section{Limitations}

We studied patients with Parkinson's disease so these results may not be applicable to healthy humans. We had a relatively small number of patients (particularly in the GP group), but this is inevitable in most invasive intraoperative recording studies. Despite stimulation parameters that varied between patients, the findings were consistent. ECoG and EMG coverage was limited so we likely missed some EPs generated by DBS. The EPs were identified visually, which could introduce bias and inconsistent selection, but analysis was done by the same investigator and without the knowledge of therapeutic contacts. We relied on clinically determined optimal contacts and did not systematically test all contacts for therapeutic benefit to correlate with intraoperative findings. We also did not quantify the degree of improvement that patients experienced with chronic stimulation. We could not compare stimulation amplitudes used clinically to those used in the operating room because impedances were not recorded during clinical visits when constant voltage stimulation was used.

\section{Conclusion}

We provide the first physiological demonstration of the corticosubthalamic hyperdirect pathway and its topography at high spatial resolution in humans. These findings should inform models of basal ganglia function and may prove useful in guiding lead placement and device programming.

\section{References}

Anderson RW, Farokhniaee A, Gunalan K, Howell B, McIntyre CC (2018) Action potential initiation, propagation, and cortical invasion in the hyperdirect pathway during subthalamic deep brain stimulation. Brain Stimul 11:1140-1150. CrossRef Medline

Aron AR, Behrens TE, Smith S, Frank MJ, Poldrack RA (2007) Triangulating a cognitive control network using diffusion-weighted magnetic resonance imaging (MRI) and functional MRI. J Neurosci 27:3743-3752. CrossRef Medline

Ashby P, Strafella A, Dostrovsky JO, Lozano A, Lang AE (1998) Immediate motor effects of stimulation through electrodes implanted in the human globus pallidus. Stereotact Funct Neurosurg 70:1-18. CrossRef Medline

Ashby P, Paradiso G, Saint-Cyr JA, Chen R, Lang AE, Lozano AM (2001) Potentials recorded at the scalp by stimulation near the human subthalamic nucleus. Clin Neurophysiol 112:431-437. CrossRef Medline

Baker KB, Montgomery EB Jr, Rezai AR, Burgess R, Lüders HO (2002) Subthalamic nucleus deep brain stimulus evoked potentials: physiological and therapeutic implications. Mov Disord 17:969-983. CrossRef Medline

Bhanpuri NH, Bertucco M, Ferman D, Young SJ, Liker MA, Krieger MD, Sanger TD (2014) Deep brain stimulation evoked potentials may relate to clinical benefit in childhood dystonia. Brain Stimul 7:718-726. CrossRef Medline

Brunenberg EJ, Moeskops P, Backes WH, Pollo C, Cammoun L, Vilanova A, Janssen ML, Visser-Vandewalle VE, ter Haar Romeny BM, Thiran JP, Platel B (2012) Structural and resting state functional connectivity of the subthalamic nucleus: identification of motor STN parts and the hyperdirect pathway. PLoS One 7:e39061. CrossRef Medline

Canteras NS, Shammah-Lagnado SJ, Silva BA, Ricardo JA (1988) Somatosensory inputs to the subthalamic nucleus: a combined retrograde and anterograde horseradish peroxidase study in the rat. Brain Res 458:53-64. CrossRef Medline

Crowell AL, Ryapolova-Webb ES, Ostrem JL, Galifianakis NB, Shimamoto S, Lim DA, Starr PA (2012) Oscillations in sensorimotor cortex in movement disorders: an electrocorticography study. Brain 135:615-630. CrossRef Medline

Degos B, Deniau JM, Le Cam J, Mailly P, Maurice N (2008) Evidence for a 
direct subthalamo-cortical loop circuit in the rat. Eur J Neurosci 27:25992610. CrossRef Medline

de Hemptinne C, Swann NC, Ostrem JL, Ryapolova-Webb ES, San Luciano M, Galifianakis NB, Starr PA (2015) Therapeutic deep brain stimulation reduces cortical phase-amplitude coupling in Parkinson's disease. Nat Neurosci 18:779-786. CrossRef Medline

Dejean C, Hyland B, Arbuthnott G (2009) Cortical effects of subthalamic stimulation correlate with behavioral recovery from dopamine antagonist induced akinesia. Cereb Cortex 19:1055-1063. CrossRef Medline

Devergnas A, Wichmann T (2011) Cortical potentials evoked by deep brain stimulation in the subthalamic area. Front Syst Neurosci 5:30. CrossRef Medline

Eusebio A, Pogosyan A, Wang S, Averbeck B, Gaynor LD, Cantiniaux S, Witjas T, Limousin P, Azulay JP, Brown P (2009) Resonance in subthalamo-cortical circuits in Parkinson's disease. Brain 132:21392150. CrossRef Medline

Fukaya C, Sumi K, Otaka T, Shijo K, Nagaoaka T, Kobayashi K, Oshima H, Watanabe T, Yamamoto T, Katayama Y (2011) Corticospinal descending direct wave elicited by subcortical stimulation. J Clin Neurophysiol 28: 297-301. CrossRef Medline

Gale J (2004) Basis of periodic activities in the basal ganglia-thalamiccortical system of the rhesus macaque. Kent, OH: Kent State University.

Gradinaru V, Mogri M, Thompson KR, Henderson JM, Deisseroth K (2009) Optical deconstruction of parkinsonian neural circuitry. Science 324: 354-359. CrossRef Medline

Gunalan K, Chaturvedi A, Howell B, Duchin Y, Lempka SF, Patriat R, Sapiro G, Harel N, McIntyre CC (2017) Creating and parameterizing patientspecific deep brain stimulation pathway-activation models using the hyperdirect pathway as an example. PLoS One 12:e0176132. CrossRef Medline

Gurney K, Prescott TJ, Redgrave P (2001) A computational model of action selection in the basal ganglia: I. A new functional anatomy. Biol Cybern 84:401-410. CrossRef Medline

Hashimoto T, Elder CM, Okun MS, Patrick SK, Vitek JL (2003) Stimulation of the subthalamic nucleus changes the firing pattern of pallidal neurons. J Neurosci 23:1916-1923. CrossRef Medline

Jobst EE, Melnick ME, Byl NN, Dowling GA, Aminoff MJ (1997) Sensory perception in Parkinson disease. Arch Neurol 54:450-454. CrossRef Medline

Kelley R, Flouty O, Emmons EB, Kim Y, Kingyon J, Wessel JR, Oya H, Greenlee JD, Narayanan NS (2018) A human prefrontal-subthalamic circuit for cognitive control. Brain 141:205-216. CrossRef Medline

Kita T, Kita H (2012) The subthalamic nucleus is one of multiple innervation sites for long-range corticofugal axons: a single-axon tracing study in the rat. J Neurosci 32:5990-5999. CrossRef Medline

Kitai ST, Deniau JM (1981) Cortical inputs to the subthalamus: intracellular analysis. Brain Res 214:411-415. CrossRef Medline

Kühn AA, Kempf F, Brücke C, Gaynor Doyle L, Martinez-Torres I, Pogosyan A, Trottenberg T, Kupsch A, Schneider GH, Hariz MI, Vandenberghe W, Nuttin B, Brown P (2008) High-frequency stimulation of the subthalamic nucleus suppresses oscillatory beta activity in patients with Parkinson's disease in parallel with improvement in motor performance. J Neurosci 28:6165-6173. CrossRef Medline

Kumaravelu K, Brocker DT, Grill WM (2016) A biophysical model of the cortex-basal ganglia-thalamus network in the 6-OHDA lesioned rat model of Parkinson's disease. J Comput Neurosci 40:207-229. CrossRef Medline

Kumaravelu K, Oza CS, Behrend CE, Grill WM (2018) Model-based deconstruction of cortical evoked potentials generated by subthalamic nucleus deep brain stimulation. J Neurophysiol 120:662-680. CrossRef Medline

Kuriakose R, Saha U, Castillo G, Udupa K, Ni Z, Gunraj C, Mazzella F, Hamani C, Lang AE, Moro E, Lozano AM, Hodaie M, Chen R (2010) The nature and time course of cortical activation following subthalamic stimulation in Parkinson's disease. Cereb Cortex 20:1926-1936. CrossRef Medline

Lambert C, Zrinzo L, Nagy Z, Lutti A, Hariz M, Foltynie T, Draganski B, Ashburner J, Frackowiak R (2012) Confirmation of functional zones within the human subthalamic nucleus: patterns of connectivity and subparcellation using diffusion weighted imaging. Neuroimage 60:83-94. CrossRef Medline

Li Q, Ke Y, Chan DC, Qian ZM, Yung KK, Ko H, Arbuthnott GW, Yung WH
(2012) Therapeutic deep brain stimulation in parkinsonian rats directly influences motor cortex. Neuron 76:1030-1041. CrossRef Medline

Li S, Arbuthnott GW, Jutras MJ, Goldberg JA, Jaeger D (2007) Resonant antidromic cortical circuit activation as a consequence of high-frequency subthalamic deep-brain stimulation. J Neurophysiol 98:3525-3537. CrossRef Medline

MacKinnon CD, Webb RM, Silberstein P, Tisch S, Asselman P, Limousin P, Rothwell JC (2005) Stimulation through electrodes implanted near the subthalamic nucleus activates projections to motor areas of cerebral cortex in patients with Parkinson's disease. Eur J Neurosci 21:1394-1402. CrossRef Medline

Mansouri A, Taslimi S, Badhiwala JH, Witiw CD, Nassiri F, Odekerken VJJ, De Bie RMA, Kalia SK, Hodaie M, Munhoz RP, Fasano A, Lozano AM (2018) Deep brain stimulation for Parkinson's disease: meta-analysis of results of randomized trials at varying lengths of follow-up. J Neurosurg 128:1199-1213. CrossRef Medline

Maruo T, Saitoh Y, Hosomi K, Kishima H, Shimokawa T, Hirata M, Goto T, Morris S, Harada Y, Yanagisawa T, Aly MM, Yoshimine T (2011) Deep brain stimulation of the subthalamic nucleus improves temperature sensation in patients with Parkinson's disease. Pain 152:860-865. CrossRef Medline

Maurice N, Deniau JM, Glowinski J, Thierry AM (1998) Relationships between the prefrontal cortex and the basal ganglia in the rat: physiology of the corticosubthalamic circuits. J Neurosci 18:9539-9546. CrossRef Medline

Milardi D, Gaeta M, Marino S, Arrigo A, Vaccarino G, Mormina E, Rizzo G, Milazzo C, Finocchio G, Baglieri A, Anastasi G, Quartarone A (2015) Basal ganglia network by constrained spherical deconvolution: a possible cortico-pallidal pathway? Mov Disord 30:342-349. CrossRef Medline

Miocinovic S, Parent M, Butson CR, Hahn PJ, Russo GS, Vitek JL, McIntyre CC (2006) Computational analysis of subthalamic nucleus and lenticular fasciculus activation during therapeutic deep brain stimulation. J Neurophysiol 96:1569-1580. CrossRef Medline

Monakow KH, Akert K, Künzle H (1978) Projections of the precentral motor cortex and other cortical areas of the frontal lobe to the subthalamic nucleus in the monkey. Exp Brain Res 33:395-403. Medline

Naito A, Kita H (1994) The cortico-pallidal projection in the rat: an anterograde tracing study with biotinylated dextran amine. Brain Res 653:251257. CrossRef Medline

Nambu A (2005) A new approach to understand the pathophysiology of Parkinson's disease. J Neurol 252:IV1-IV4. CrossRef Medline

Nambu A, Takada M, Inase M, Tokuno H (1996) Dual somatotopical representations in the primate subthalamic nucleus: evidence for ordered but reversed body-map transformations from the primary motor cortex and the supplementary motor area. J Neurosci 16:2671-2683. CrossRef Medline

Ni Z, Kim SJ, Phielipp N, Ghosh S, Udupa K, Gunraj CA, Saha U, Hodaie M, Kalia SK, Lozano AM, Lee DJ, Moro E, Fasano A, Hallett M, Lang AE, Chen R (2018) Pallidal deep brain stimulation modulates cortical excitability and plasticity. Ann Neurol 83:352-362. CrossRef Medline

Ostrem JL, San Luciano M, Dodenhoff KA, Ziman N, Markun LC, Racine CA, de Hemptinne C, Volz MM, Heath SL, Starr PA (2017) Subthalamic nucleus deep brain stimulation in isolated dystonia: a 3-year follow-up study. Neurology 88:25-35. CrossRef Medline

Panov F, Levin E, de Hemptinne C, Swann NC, Qasim S, Miocinovic S, Ostrem JL, Starr PA (2017) Intraoperative electrocorticography for physiological research in movement disorders: principles and experience in 200 cases. J Neurosurg 126:122-131. CrossRef Medline

Plantinga BR, Roebroeck A, Kemper VG, Uludağ K, Melse M, Mai J, Kuijf ML, Herrler A, Jahanshahi A, Ter Haar Romeny BM, Temel Y (2016) Ultrahigh field MRI post mortem structural connectivity of the human subthalamic nucleus, substantia nigra, and globus pallidus. Front Neuroanat 10:66. CrossRef Medline

Sanders TH, Jaeger D (2016) Optogenetic stimulation of cortico-subthalamic projections is sufficient to ameliorate bradykinesia in 6-ohda lesioned mice. Neurobiol Dis 95:225-237. CrossRef Medline

Smith Y, Wichmann T (2015) The cortico-pallidal projection: an additional route for cortical regulation of the basal ganglia circuitry. Mov Disord 30:293-295. CrossRef Medline

Smith Y, Wichmann T, DeLong MR (1994) Synaptic innervation of neu- 
rones in the internal pallidal segment by the subthalamic nucleus and the external pallidum in monkeys. J Comp Neurol 343:297-318. CrossRef Medline

Smith Y, Charara A, Hanson JE, Hubert GW, Kuwajima M (2001) Chemical anatomy and synaptic connectivity of the globus pallidus and subthalamic nucleus. In: Basal ganglia and thalamus in health and movement disorders (Kultas-Ilinsky K, Ilinsky IA, eds), pp 119-134. Boston: Springer.

Starr PA (2002) Placement of deep brain stimulators into the subthalamic nucleus or globus pallidus internus: technical approach. Stereotact Funct Neurosurg 79:118-145. CrossRef Medline

Swann NC, de Hemptinne C, Miocinovic S, Qasim S, Ostrem JL, Galifianakis NB, Luciano MS, Wang SS, Ziman N, Taylor R, Starr PA (2018) Chronic multisite brain recordings from a totally implantable bidirectional neural interface: experience in 5 patients with Parkinson's disease. J Neurosurg 128:605-616. CrossRef Medline

Tisch S, Rothwell JC, Zrinzo L, Bhatia KP, Hariz M, Limousin P (2008)
Cortical evoked potentials from pallidal stimulation in patients with primary generalized dystonia. Mov Disord 23:265-273. CrossRef Medline

Udupa K, Bahl N, Ni Z, Gunraj C, Mazzella F, Moro E, Hodaie M, Lozano AM, Lang AE, Chen R (2016) Cortical plasticity induction by pairing subthalamic nucleus deep-brain stimulation and primary motor cortical transcranial magnetic stimulation in Parkinson's disease. J Neurosci 36: 396-404. CrossRef Medline

Walker HC, Huang H, Gonzalez CL, Bryant JE, Killen J, Cutter GR, Knowlton RC, Montgomery EB, Guthrie BL, Watts RL (2012) Short latency activation of cortex during clinically effective subthalamic deep brain stimulation for Parkinson's disease. Mov Disord 27:864-873. CrossRef Medline

Zaidel A, Spivak A, Grieb B, Bergman H, Israel Z (2010) Subthalamic span of beta oscillations predicts deep brain stimulation efficacy for patients with Parkinson's disease. Brain 133:2007-2021. CrossRef Medline 